\title{
Heat stress in Marchantia polymorpha: sensing and mechanisms underlying a dynamic response
}

Fernanda Marchetti $^{1 \S}$, Maximiliano Cainzos $^{1 \S}$, Milagros Cascallares ${ }^{1}$, Ayelén Mariana Distéfano $^{1}$, Nicolás Setzes ${ }^{1}$, Gabriel Alejandro López ${ }^{1}$, Eduardo Zabaleta ${ }^{1}$, Gabriela Carolina Pagnussat $^{1^{*}}$

${ }^{1}$ Instituto de Investigaciones Biológicas, Universidad Nacional de Mar del Plata, CONICET, Mar del Plata, Argentina.

${ }^{\S}$ Fernanda Marchetti and Maximiliano Cainzos should be considered as joint first author

* Corresponding author, gpagnussat@mdp.edu.ar

\section{Running head: Heat stress in Marchantia polymorpha}

\begin{abstract}
Sensing and response to high temperatures are crucial to prevent heat-related damage and to preserve cellular and metabolic functions. The response to heat stress is a complex and coordinated process that involves several subcellular compartments and multi-level regulatory networks that are synchronized to avoid cell damage while maintaining cellular homeostasis. In this review, we provide an insight into the most recent advances in elucidating the molecular mechanisms involved in heat stress sensing and response in Marchantia polymorpha. Based on
\end{abstract}

This article has been accepted for publication and undergone full peer review but has not been through the copyediting, typesetting, pagination and proofreading process which may lead to differences between this version and the Version of Record. Please cite this article as doi: $10.1111 /$ pce.13914 
the signaling pathways and genes that were identified in Marchantia, our analyses indicate that although with specific particularities, the core components of the heat stress response seem conserved in bryophytes and angiosperms. Liverworts not only constitute a powerful tool to study heat stress response and signaling pathways during plant evolution, but also provide key and simple mechanisms to cope with extreme temperatures. Given the increasing prevalence of high temperatures around the world as a result of global warming, this knowledge provides a new set of molecular tools with potential agronomical applications.

Keywords: Heat stress, Marchantia, stress response, bryophyte, heat sensing 


\section{Introduction}

With increasing extreme heat events associated with climate change, understanding how plants sense and respond to high temperatures is crucial to prevent damage and preserve cellular and metabolic functions.

Depending on the exposure time and temperature, plants can develop different responses that range from acclimation to the activation of specific cell death programs in particular cells or tissues. The pathways that govern these responses are complex and depend not only on the extent of the stress applied but also on previous growing temperatures and other environmental conditions including light intensity and humidity (Wang et al. 2016). In addition, plants at a particular developmental stage also respond differentially to heat stress (HS), adding more complexity to heat stress response studies, which can certainly be challenging. In this sense, the bryophyte Marchantia polymorpha is emerging as an interesting and simpler model organism to study stress response. Although recent phylogenetic studies question the basal position of liverworts in the phylogeny of land plants (de Sousa et al. 2019; Puttick et al. 2018; Sousa et al. 2020; Zhang et al. 2020) (Figure 1A), its study emerges as a useful opportunity to understand biochemical and molecular pathways in an organism that presents low genetic redundancy that might have an early evolutionary origin (Bowman et al. 2017). M. polymorpha is a member of Marchantiopsida, a clade characterized by a complex gametophytic thallus. Marchantia has a dominant haploid gametophytic generation, which can be easily reproduced asexually through gemmae. As each gemma develops from a single cell by mitosis, isogenic lines can be easily 
established. In addition, it only takes $2-3$ weeks for a gemma to grow into a gemmae-producing thallus and gemmae can be preserved for several years. These characteristics, together with its small genome size, constitute Marchantia as a widely used model organism for molecular, physiological, biochemical/genetic studies and evolutionary research. In fact, sequencing of the M. polymorpha genome revealed that key aspects of plant growth, development and stress response signaling pathways are conserved. Several of these pathways emerged during water-toland transition. As transition from aquatic to terrestrial environments required overcoming extreme temperature fluctuations, the study of heat stress sensing and response in Marchantia not only offers an evolutionary perspective but also might provide opportunities to apply this knowledge to develop biotechnological tools that might help to cope with heat waves expected because of climate change.

\section{Sensing of high temperatures}

It is widely accepted that an increase in the environmental temperature alters the plasma membrane fluidity of plant cells and activates membrane heat receptors (Hou et al. 2016; Török et al. 2014). Heat stress also results in the accumulation of unfolded proteins and reactive oxygen species (ROS) inside the cell. All these changes stimulate a plethora of signal transduction pathways that regulate the expression of specific genes, allowing the plant to tolerate stress and to survive. As high temperatures produce alterations in macromolecules (i.e. protein misfolding/denaturation or partial melting of DNA-RNA complexes), it has been postulated that 
any of these changes might serve as a sensor of heat. However, the definition of a true primary abiotic sensor has been recently revised (Lamers et al. 2020). It has been proposed that a sensor needs to perceive the stress by detecting suboptimal environmental conditions and to activate a specific cellular signaling pathway that triggers a unique and coordinated response to the stress (Lamers et al. 2020).

Several components of the plasma membrane have been postulated as primary heat sensors in plants as they are able to respond to small changes in temperature. Responses to high temperatures involve alterations in the plasma membrane lipid composition and also the interaction between lipids and specific membrane proteins. This membrane remodeling triggers downstream signaling pathways that determine the intracellular response to the stress perceived (Mittler et al. 2012; Saidi et al. 2010). Heat related changes in plasma membrane fluidity are associated with a specific transient $\mathrm{Ca}^{2+}$ influx across the plasma membrane (Gong et al. 1998; Liu et al. 2006; Saidi et al. 2009; Wu and Jinn 2010).

Plant CNGCs (plasma membrane-embedded Cyclic Nucleotide-gated $\mathrm{Ca}^{2+}$ Channels) are involved in responses to biotic and abiotic stresses, and in development and fertilization (DeFalco et al. 2016; Dietrich et al. 2010; Kaplan et al. 2007; Moeder et al. 2011). OsCNGC14 and OsCNGC16 modulate calcium signals in response to extreme temperatures and are required for heat and chilling tolerance in rice (Cui et al. 2020).

The Arabidopsis genome contains 20 CNGC family members that exhibit variable levels of expression in different tissues (Talke et al. 2003) and are classified into five subgroups (I-III, IVa 
and IVb) based on their sequence similarity (Mäser 2001). Interestingly, CNGCb from Physcomitrium patens and its orthologs CNGC2 and CNGC4 from Arabidopsis are essential components of the thermosensory machinery of land plant cells. P. patens impaired in CNGCb show hypersensitive temperature-dependent $\mathrm{Ca}^{2+}$ and hyper-thermoresponsive profiles of heat stress response activation. A similar phenotype was shown for Arabidopsis CNGC2 mutants (Finka and Goloubinoff 2013; Finka et al. 2011). These reports indicate that temperature sensing via CNGC might be a highly conserved mechanism. A search in the genomic sequence databases of M. polymorpha revealed the presence of five CNGC encoding genes (Mp6g01920.1, Mp4g04110.1, Mp5g07780.1, Mp4g11640.1 and Mp3g14660.1). A phylogenetic analysis comparing CNGC proteins from Arabidopsis thaliana, $P$. patens and M. polymorpha shows that two MpCNGC proteins (encoded by Mp4g11640.1 and Mp3g14660.1) are grouped together in Group IVa with the P. patens proteins CNGCb and CNGCd and Arabidopsis AtCNGC2 and AtCNGC4, suggesting that a similar mechanism in response to HS could take place in Marchantia. In addition, MpCNGCs display the same protein domain architecture as the other proteins present in Group IVa and a high degree of identity, reinforcing the idea that they could play a similar role in Marchantia (Figure 1).

Light and temperature share common sensors and regulators in plants. These include PHYTOCHROME-INTERACTING FACTORs (PIFs), which are key repressors of photomorphogenesis. Red light converts the inactive form of phytochrome B (phyB), Pr, into the active Pfr form, which interacts with PIF proteins (Shen et al. 2008; Zhu et al. 2000). 
Importantly, high temperatures spontaneously revert the light-activated Pfr form of phyB back to the inactive Pr form in a process called thermal reversion that is light-independent. Therefore, phyB and other phytochromes have emerged as major sensors in Arabidopsis, integrating both light and temperature cues (Jung et al. 2015; Legris et al. 2016; Vu et al. 2018). Similarly to phyB in Arabidopsis, high temperatures shorten the lifetime of the photoactivated PHOTOTROPIN (MpPHOT) (Komatsu et al. 2014), which is the homolog of the blue light receptor AtPHOT2 (Fujii et al. 2017) and has been proposed as a thermosensor in Marchantia (Fujii et al. 2017; Vu et al. 2018). Phototropins contain two Light Oxygen or Voltage (LOV) domains at their N-terminal domain that is able to bind to a flavin mononucleotide (FMN) chromophore. In darkness, the LOV domain is inactive and non-covalently bonded to FMN. Upon blue light excitation, the LOV domain covalently binds to the FMN conferring the active state. The active status is thermoreversible, as an increase in temperature causes the active LOV domain to disconnect from the FMN and to return to the inactive state. MpPHOT has been shown to regulate cold-induced chloroplast movement, avoiding photooxidative damage. High temperatures cause the reversion of MpPHOT to an inactive state, preventing the response (Fujii et al., 2017). In Arabidopsis, phototropins act as thermosensors driving high temperaturemediated guard cell movement (Kostaki et al. 2020). In response to high temperatures, stomata opening results in increased evapotranspiration and leaf cooling (Kostaki et al. 2020). However, the scenario in Marchantia spp seems different. Since Marchantia pores do not act as stomata and 
warm temperatures have been shown to inactivate MpPHOT, (Fujii et al., 2017), it is not clear how phototropin activity would lead a response to high temperatures.

Several articles report that leucine-rich repeat receptor-like protein kinases (LRR-RLKs) might also act as heat sensors. In A. thaliana, two LRR-RLKs (ERECTA and AtPXL1) are involved in heat stress response (Jung et al. 2015; Qi et al. 2004). AtPXL1 is induced upon heat stress and phosphorylates histidine-rich dehydrin1 (AtHIRD1) and light-harvesting protein complex I (AtLHCA1), which are likewise involved in different types of stresses such as high light/heat stress and salt/drought stress, respectively (Hara et al. 2011; Ivanov et al. 2017). Furthermore, the genes encoding Solanum tuberosum Receptor-like Kinase 1 (StRLK1) and Oryza sativa gamma-ray induced LRR-RLK1 (OsGIRL1) receptors are also induced during heat shock treatments (Park et al. 2014; Wu et al. 2009). Homologues of AtPXL1 and ERECTA are found in Marchantia and known as TDIF RECEPTOR (MpTDR) and ERECTA (MpER) respectively, although their roles in heat stress sensing is still uncertain (Hirakawa et al. 2019).

Additionally, a recent study in Arabidopsis revealed a central role for chloroplast signaling regulating the level of response to high temperatures (Dickinson et al. 2018). Light-activated chloroplast induces the expression of heat-related genes such as HSP70, resulting in a diurnal pattern of thermotolerance. Concordantly with a central role for chloroplasts sensing high temperatures and regulating a transcriptional response, it has been shown that a heat-responsive retrograde pathway dependent on chloroplast translation capacity is critical for the activation of HSFA2 and its target genes in Arabidopsis (Yu et al. 2012). In fact, it has been suggested by 
structural and functional studies, that chloroplast retrograde signaling is conserved in several species including flowering plants, the fern Ceratopteris richardii, and the moss P. patens (Zhao et al. 2019). A summary of the heat-sensing mechanisms that might be functional in Marchantia is shown in Figure 2.

\section{Reactive oxygen species (ROS) accumulation in response to heat stress}

Calcium ions and heat sensors transfer signals to transcription factors through a series of signaling cascades. $\mathrm{Ca}^{2+}$ signaling has been linked to regulatory mechanisms of ROS-producing enzymes (Dat et al. 1998; Foyer et al. 1997; Mittler et al. 2012). Although an excess of ROS causes detrimental effects on plant cells, ROS have been widely recognized as molecules mediating stress response and development (Mhamdi and Van Breusegem 2018; Schippers et al. 2016; Waszczak et al. 2016). In particular, heat-shock transcription factors (HSFs) are proposed to directly sense ROS, regulating the expression of oxidative stress response genes ( $\mathrm{Li}$ et al. 2018).

Since ROS production by plant NADPH oxidases/RBOHs (Respiratory Burst Oxidase Homologues) is synergistically activated by $\mathrm{Ca}^{2+}$ binding to their EF-hand motif, they have been implicated as a crosstalk point in the ROS- $\mathrm{Ca}^{2+}$ signaling network (Dietz et al. 2016; Kadota et al. 2015; Mittler et al. 2012; Mittler et al. 2004; Suzuki et al. 2011; Torres and Dangl 2005). There are about 10 isoforms of RBOH enzymes described in A. thaliana (Torres and Dangl 2005; Torres et al. 1998). Particularly, RBOHD is a key player in ROS production under 
stressful conditions (Kadota et al. 2015; Katano et al. 2018; Miller et al. 2009; Miller et al. 2007; Mittler et al. 2012; Sagi and Fluhr 2001). Experiments performed in A. thaliana mutant plants lacking RBOHD show that the systemic response to heat stress is largely dependent on RBOHD activity (Miller et al. 2009). Only two RBOH isoforms are encoded by the M. polymorpha genome, which suggests far less functional redundancy. These two isoforms, Mp3g20340.1 and Mp7g00270.1 (Kimura et al. 2020), display conserved C-terminal phosphorylation sites, suggesting that regulation by the $\mathrm{Ca}^{2+}$ signal might be also conserved.

Other important sources of ROS during HS constitute the mitochondria and chloroplasts. Mitochondria play a crucial role in setting the cellular redox-state and in triggering signal transduction pathways upon stress. In A. thaliana, the induction of heat shock proteins (HSPs) after a heat stress treatment was shown to require mitochondrial ROS production (Zhang et al. 2009). Remarkably, it is suggested that ROS accumulation is sensed by HSFs, linking heat stress responses with the ROS signaling network (Davletova et al. 2005). Although a similar mechanism could take place in Marchantia upon exposure to high temperatures, the role of mitochondria during this process remains far largely unknown.

Particularly, photosynthesis is highly sensitive to high temperatures and heat can lead to an alteration of the redox state. HS is reported to affect thylakoid membranes, photosystems PSI and PSII, the cytochrome b6f (Cytb6f) complex and Rubisco, leading to the inhibition of various redox and metabolic reactions (Mathur et al. 2014). In M. polymorpha, ROS accumulation triggers the activation of the chloroplast genes MpSIG1, MpSIG2 and MpSIG5 (plastid RNA 
polymerase sigma factors), which are thought to regulate the chloroplast transcriptome during stressful environmental conditions (Kanazawa et al. 2013; Zhao et al. 2017), a response that was also observed in Arabidopsis plants in response to HS (Danilova et al. 2018).

Interestingly, activation of AtPHOT2 (to which MpPHOT is analogous) induces an increase in cytoplasmic $\left[\mathrm{Ca}^{2+}\right]$, promoting ROS production via $\mathrm{RBOH}$ activation (Wen et al. 2008). In addition, the transcription factor MpTCP1 (TEOSINTE BRANCHED 1, CYCLOIDEA, PCF1), with evolutionarily conserved roles across the plant kingdom, has been proposed as a sensor of altered redox conditions that can also play a role as a modulator of the Marchantia transcriptome in response to heat stress (Busch et al. 2019). Specifically, MpTCP1 senses ROS levels and regulates a complex network of ROS producing and detoxifying enzymes, mediating adaptive responses. Although further studies are needed to decipher ROS signaling and crosstalk pathways during heat stress in Marchantia, it is currently thought that ROS signaling is part of the regulatory pathways triggered in response to high temperatures from the early stages of land plant evolution (de Vries et al. 2020). As different stress pathways in Marchantia and Physcomitrium seem intertwined with ROS and retrograde signaling, plant terrestrialization might have included not only ROS signaling but also components of the retrograde-signaling pathway (de Vries et al. 2018). The mechanisms proposed to mediate Marchantia ROS accumulation in response to HS are illustrated in Figure 3.

\section{Transcriptional responses to heat stress}


When environmental temperatures rise, plants respond in a conserved manner through a process known as heat stress response (Saidi et al. 2010). This process is mainly characterized by the massive up-regulation of genes encoding HSPs (Finka et al. 2011), a response that is highly conserved and is also found in animals, yeast and prokaryotes. The activation of the heat stress response involves $0.5-1 \%$ of the total genome, including HSPs with chaperone function as the most abundantly expressed (Finka et al. 2011). Chaperones are key components in the heat stress response process due to the fact that they are timely expressed to prevent heat damage and contribute to thermotolerance in plants (Hua 2009; Larkindale and Vierling 2008). In addition to HSPs, thermotolerance is also dependent on the accumulation of specific metabolites and plant hormones triggered pathways (Hua 2009; Iba 2002).

HSFs are critical components of the response to heat stress, activating the transcription of HSPs (Baniwal et al. 2004; Koskull-Döring et al. 2007). Members of the HSF A1 family (HSFA1s) are known as master regulators of the heat stress response in plants. Heat-induced gene expression is regulated by HSFs at different subcellular levels which operate simultaneously to develop a coordinated response (Sajid et al. 2018). During $\mathrm{HS}, \mathrm{Ca}^{2+}$ regulates HsfA1s, which directly interacts with HSFA2 and HSFA1a via calmodulin 3 (CaM3) and a calcium/calmodulin binding protein-kinases (CBK) to regulate HSP gene expression (Sajid et al. 2018). In Arabidopsis, AtCAM3 activates several HSFs including the Multiprotein Bridging Factor 1C (MBF1c) (Katano et al. 2018), a WRKY DNA-binding domain superfamily protein (WRKY39) (Li et al. 2009; Ohama et al. 2017) and several HSFA1s (Zhang et al. 2009). 
There are a few reports on the role of HSFAs in bryophytes. In Physcomitrium, it was proposed that the regulation of PpHSFA1-1 at the post-transcriptional level is similar to that of AtHSFA2 (Chang et al. 2014). Moreover, a recent study assessing the $P$. patens transcriptome remodeling during acclimation to high temperatures revealed that an early response to heat stress involved HSPs related to protein folding and endoplasmic reticulum stress. Through a Weighted Gene Correlation Network Analysis, an HSFA1E binding motif was identified within the promoters of unrelated genes that displayed rapid heat-activation, suggesting that those genes might be direct targets of HSFA1E transcription factors upon heat stress (Elzanati et al. 2020). A search in the M. polymorpha genome revealed the presence of two genes encoding for HSFs (Mapoly0018s0001 and Mapoly0011s0205) (Liu et al. 2019a). Since Mapoly0018s0001 (named MpHSF2, (Liu et al. 2019a) belongs to the HSFA family, it arises as a good candidate to regulate the transcription of Marchantia HSPs in response to heat stress (Figure 4).

In plants exposed to heat stress, members of the group II of MBF1 proteins translocate to the nucleus in a ROS-dependent manner. This translocation results in the expression of a set of proteins involved in the heat stress response, such as DREB2A, HSFB2a and HSFB2b (JaimesMiranda and Montes 2020). In the case of MBF1c, it also modulates the metabolism of trehalose, salicylic acid and ethylene (Suzuki et al. 2008; Suzuki et al. 2013). The primary structure of MBF1 proteins is somewhat conserved among plants. MARPO_0105s0012 from M. polymorpha is described as the homologous of MBF1c, a member of the group II of MBF proteins (Jaimes- 
Miranda and Montes 2020; Tsuda and Yamazaki 2004) although its function in Marchantia remains to be elucidated.

HSPs are classified into five classes according to their molecular weight. In angiosperms, HSP70 and HSP90 are key components during the heat stress response because they directly regulate HSFA1s (Jacob et al. 2017; Swindell et al. 2007). Under normal conditions, HSP70 and HSP90 repress HSFA1s activity. Upon heat treatment, HSFA1 is released from HSP70/90 repression and becomes active (Ohama et al. 2017). While the Arabidopsis HSP70 superfamily has 18 members and P. patens has 21 (Tang et al. 2016), there are at least 11 HSP70s reported in M. polymorpha. For HSP90, there are 7 encoding genes in Arabidopsis (Krishna and Gloor 2001), 10 in $P$. patens (Zhang et al. 2013) and at least 5 putative HSP90 encoding genes in the M. polymorpha genome (Table 1). Experiments in P. patens showed that inhibition of HSP90 triggers a heat-shock-like response, inducing the expression of HSFs in a process that is $\mathrm{Ca}^{2+}$ dependent (Saidi et al. 2009; Yamada et al. 2007). In addition, PpHSP17.3b and PpHSP16.4, encoding cytosolic small HSPs, are induced during heat stress and plants impaired in PpHSP16.4 show delayed recovery after heat treatment (Ruibal et al. 2013; Saidi et al. 2005). In agreement with a similar role in M. polymorpha, MpHSP17.8A1 (MARPO_0076s0004) gene was shown to be highly induced after a heat treatment of 1 hour (Nishihama et al. 2016) (Figure 4).

In Arabidopsis, HSP90 is also essential for stabilization of ZEITLUPE (ZTL), an E3 ubiquitin ligase that is a fundamental component of the central oscillator (Kim et al. 2011). In response to heat stress, ZTL and HSP90 are localized to protein aggregates that are degraded via the 
ubiquitin-proteasome pathways (Gil et al. 2017). Since ZTL orthologues were identified in the genomes of nonvascular and vascular land plants, including M. polymorpha (Kubota et al. 2014), it is thought that the ZTL/HSP90 module might have an ancient origin. As early land plants were likely facing extreme temperature fluctuations and high soil temperatures, it is currently accepted that the ZTL/HSP90 module might have evolved in the earliest land plants to ensure thermostable growth (Gil and Park 2019). Remarkably, transcriptomic studies in M. polymorpha and $P$. patens show induction of circadian clock components upon heat stress that indicate an early origin of a thermostable clock system and its involvement during heat stress response (Elzanati et al. 2020; Flores-Sandoval et al. 2018).

\section{Phytohormones related to heat stress response}

One of the pathways that is strongly modified during plant HS is the abscisic acid (ABA) signaling pathway. ABA is known to mediate plant heat tolerance in Arabidopsis and Festuca arundinacea (known as tall fescue) (Wang et al. 2017). It is reported that ABA induces the expression of several HSPs through an HSFA2-dependent pathway, leading to an improved heat tolerance (Islam et al. 2018; Li et al. 2014; Wang et al. 2017). In addition, HSFA6b was shown to play a pivotal role in the response to ABA and thermotolerance (Huang et al. 2016). As other signaling pathways in plants, the ABA pathway is constitutively repressed. ABA levels increase in response to environmental changes such as HS, which is sensed by ABA receptors 
(PYR/PYL/RCAR) (Zhang et al. 2019a), triggering the activation of downstream signaling cascades (Bulgakov et al. 2019; Wang and Song 2014; Zhang et al. 2019b).

Functional components of the core $\mathrm{ABA}$ transduction pathway are present from aquatic charophyte algae to angiosperms (Sun et al. 2019). In fact, MpPYL1 was shown to be a functional ABA receptor of M. polymorpha, as was able to complement Arabidopsis mutants (Bowman et al. 2017). Also, a core ABA signaling module was identified and characterized in Marchantia (Jahan et al. 2019; Lind et al. 2015; Tougane et al. 2010; Bowman et al. 2017; Eklund et al., 2018), although its role in HS response is still unclear (Figure 5). An interesting hypothesis is that ABA co-option allowed early land plants to regulate this ancestral signaling pathway in response to dehydration and extreme temperatures, enabling their establishment on land. ABA acts as a key regulator of the stomatal aperture (Bright et al. 2006), which is associated with heat dissipation and water loss management (Devireddy et al. 2020; Haworth et al. 2018; Liu et al. 2016; Zandalinas et al. 2016). Remarkably, a recent phylogenetic study found that the absence of stomata in Marchantia was a result of reductive evolution. This was succeeded by air pore acquisition, which regulates gas exchange in Marchantia (Harris et al. 2020). Unlike plants with stomatal regulation, it is believed that the air pores of Marchantia do not change their aperture size (Shimamura 2016). The regulation of stomatal closure through chloroplast retrograde signaling appears to be conserved among land plants, except in Marchantia, where the size of the air pore is not affected (Zhao et al. 2019). Due to the 
morphological differences that exist in comparison with other land plants, the role of ABA signaling in response to heat stress remains to be elucidated in Marchantia.

Jasmonic acid (JA) is another phytohormone that regulates the transcription of genes that respond to heat stress via HSFA-1 (Muench et al. 2016). The core of the JA signaling pathway proposed in angiosperms is constituted by the hormone jasmonoy-l-lisoleucine (JA-L-ILE), the Coronatine Insensitive 1 (COI-1) receptor and the Jasmonate Zim Domain (JAZ) proteins, a group of transcriptional repressors (Chini et al. 2007; Fonseca et al. 2009; Sheard et al. 2010). One MpCOI-1 and one MpJAZ protein are present in M. polymorpha (Monte et al. 2018a; Monte et al. 2018b). Although JA-Ile is not synthesized in Physcomitrium (Stumpe et al. 2010) or Marchantia, dn-OPDA (a precursor of JA-L-ILE) can act as a ligand of MpCOI1 (Monte et al. 2018a). Remarkably, a recent study by Monte et al. (2020) showed that dn-OPDA can also act independently of MpCOI1 activating HSP and antioxidant enzymes upon heat stress (Figure 5). Not only OPDA and dn-OPDA are accumulated in Marchantia in response to high temperature, but pretreatment with dn-OPDA is sufficient to confer thermotolerance as it was reported for JA in angiosperms (Clarke et al. 2009; Monte et al. 2020; Muench et al. 2016). These important findings indicate that the COI1-independent signaling is an ancient and conserved pathway, whose ancestral role was to protect plants against heat stress.

Auxins also participate in the regulation of heat responses. The addition of auxin prevents male sterility caused by heat stress in barley (Oshino et al. 2011) and regulates the auxin signaling pathway in the acquisition of thermotolerance (Kruszka et al. 2014). Additionally, high 
temperatures promote auxin-mediated hypocotyl elongation in Arabidopsis (Kim et al. 2020). All components of the auxin transcriptional response machinery are present in $M$. polymorpha as single orthologs: MpTOPLESS (TPL), MpTRANSPORT INHIBITOR RESPONSE 1 (TIR1) auxin receptor and a single ortholog of each class of AUXIN RESPONSE FACTORs (MpARF1, MpARF2 and MpARF3 (Flores-Sandoval et al. 2015b; Kato et al. 2015). Interestingly, an extensive transcriptomic study focused on the expression of MpARFs showed that several transcription factors related to auxin response are co-expressed with MpHSR after a heat shock (Flores-Sandoval et al. 2018) (Figure 5).

Altogether, these reports not only indicate the relevance of hormone signaling pathways regulating Marchantia response to heat stress, but also highlight the use of $M$. polymorpha as a model plant to understand the evolutionary mechanisms behind the involvement of plant hormones in the adaptive mechanisms triggered by extreme temperatures (Figure 5).

\section{Epigenetic regulation during heat stress}

Several epigenetic mechanisms are reported to participate in thermotolerance acquisition. These include modifications in DNA, histones, chromatin remodeling, microRNAs (miRNAs) regulation, among others (Liu et al. 2015). In particular, covalent histone modifications through acetylation or deacetylation by histone acetyltransferases (HATs) or histone deacetylases (HDACs) activities respectively, have been associated to the regulation of heat stress response gene expression (Buszewicz et al. 2016; Liu et al. 2015; Popova et al. 2013; Smith et al. 2004; 
Xue-Franzén et al. 2013). The M. polymorpha genome encodes for seven MpHAT and twelve MpHDAC genes (Bowman et al. 2017) whose expression is affected by high temperatures (Chu and Chen 2018), indicating that they might also participate in the heat stress response (Figure 6).

Plant response to heat stress also involves miRNA regulation. Several miRNAs are induced by heat in vascular plants, including miR156, miR159, miR398 and miR160 (Sunkar et al. 2012). In particular, miR319/159 and miR160 are found in the M. polymorpha genome (Lin et al. 2016) and interestingly, its target gene MpARF3 expression is suppressed during heat stress in Marchantia (Flores-Sandoval et al. 2015a; Flores-Sandoval et al. 2018).

Although information about chromatin remodeling and heat stress is scarce, new evidence shows the involvement of histone modifications in thermo-regulated gene expression. For instance, the chromatin remodeling factor PICKLE (PKL) plays a role promoting hypocotyl elongation in response to high temperatures. PKL modulates the methylation status of H3K27 and activates the expression of auxin-responsive and growth-promoting genes in Arabidopsis. Remarkably, AtHSFA2 directly activates the H3K27me3 demethylase RELATIVE OF EARLY FLOWERING 6 (REF6), which in turn de-represses HSFA2, coordinating an epigenetic network involving histone demethylases and transcription factors that ensures reproductive success and transgenerational stress adaptation (Liu et al. 2019b). Recently, it was found that H3K27me3 played an essential role in heterochromatin function in M. polymorpha (Montgomery et al. 2020), where it was postulated that marks in H3K27me3 play a role in transposon silencing 
(Figure 6). However, its role during heat stress response in Marchantia needs to be further investigated.

In addition, H2A.Z, a histone variant involved in transcriptional control, DNA repair and regulation of centromeric heterochromatin that is conserved in Marchantia, has been also implicated in plant heat response in Arabidopsis (Cortijo et al., 2017). H2A.Z is mainly associated with repressive marks and low gene expression. At non-inducible temperatures, H2A.Z-nucleosomes are enriched at heat stress-responsive genes. In response to high temperatures, HSF1 is required for the temporary eviction of H2A.Z from the bodies of repressed genes (Cortijo et al. 2017). Remarkably, a role of H2A.Z modulating H3K27me3 marking has also been proposed (Carter et al. 2018). Although these modulatory aspects of heat stress response regulation are still unexplored in liverworts, this promising possibility should be verified in future studies.

\section{Concluding remarks and perspectives}

Heat stress response is a complex process that involves several components located in different subcellular compartments. These molecules are synchronized to trigger a coordinated response to avoid cell damage caused by high temperatures. In this review, we summarized the information available about the molecular events related to heat stress response in $M$. polymorpha compared with other bryophytes and vascular plants. How plants sense heat is still a controversial topic. However, based on the signaling pathways and heat stress related genes that 
were identified in M. polymorpha, it appears that the core components of the heat stress response are conserved between bryophytes and higher plants (Figure 7). Due to their evolutionary history, liverworts constitute not only a powerful tool to study the signaling pathways and molecular responses to high temperatures during plant evolution, but also might provide key and simple mechanisms for angiosperms to cope with extreme fluctuations in temperature that are expected due to the current climate change.

\section{Acknowledgments}

We thank the International Centre for Genetic Engineering and Biotechnology (ICGEB) and The Argentinean Agency for the promotion of Science and Technology (ANPCyT) for financial support; (ICGB-CRP/19/020 grant to GCP; ANPCyT PICTs 2017-00201 and 2016-00110 to GCP; PICT 2016-00382 to AMD). GAL is an ANPCyT doctoral fellow; FM is an ANPCyT post-doctoral fellow; NS, MC and MC are CONICET fellows; AMD, EZ and GCP are CONICET researchers.

\section{Conflict of interest}

The authors declare that they have no conflict of interest.

\section{References}


Baniwal, S.K., Bharti, K., Chan, K.Y., Fauth, M., Ganguli, A., Kotak, S., et al. (2004) Heat stress response in plants: a complex game with chaperones and more than twenty heat stress transcription factors. Journal of biosciences 29: 471-487.

Bowman, J.L., Kohchi, T., Yamato, K.T., Jenkins, J., Shu, S., Ishizaki, K., et al. (2017) Insights into Land Plant Evolution Garnered from the Marchantia polymorpha Genome. Cell 171: 287-304 e215.

Bright, J., Desikan, R., Hancock, J.T., Weir, I.S. and Neill, S.J. (2006) ABA-induced NO generation and stomatal closure in Arabidopsis are dependent on H2O2 synthesis. The Plant Journal 45: 113122.

Bulgakov, V.P., Wu, H.C. and Jinn, T.L. (2019) Coordination of ABA and Chaperone Signaling in Plant Stress Responses. Trends Plant Sci 24: 636-651.

Busch, A., Deckena, M., Almeida-Trapp, M., Kopischke, S., Kock, C., Schüssler, E., et al. (2019) MpTCP1 controls cell proliferation and redox processes in Marchantia polymorpha. The New phytologist 224.

Buszewicz, D., Archacki, R., Palusiński, A., Kotliński, M., Fogtman, A., Iwanicka-Nowicka, R., et al. (2016) HD2C histone deacetylase and a SWI/SNF chromatin remodelling complex interact and both are involved in mediating the heat stress response in Arabidopsis. Plant, cell \& environment 39: 2108-2122.

Carter, B., Bishop, B., Ho, K.K., Huang, R., Jia, W., Zhang, H., et al. (2018) The Chromatin Remodelers PKL and PIE1 Act in an Epigenetic Pathway That Determines H3K27me3 Homeostasis in Arabidopsis. The Plant Cell 30: 1337-1352. 
Clarke, S.M., Cristescu, S.M., Miersch, O., Harren, F.J., Wasternack, C. and Mur, L.A. (2009) Jasmonates act with salicylic acid to confer basal thermotolerance in Arabidopsis thaliana. The New phytologist 182: 175-187.

Cortijo, S., Charoensawan, V., Brestovitsky, A., Buning, R., Ravarani, C., Rhodes, D., et al. (2017) Transcriptional Regulation of the Ambient Temperature Response by H2A.Z Nucleosomes and HSF1 Transcription Factors in Arabidopsis. Mol Plant 10: 1258-1273.

Cui, Y., Lu, S., Li, Z., Cheng, J., Hu, P., Zhu, T., et al. (2020) CYCLIC NUCLEOTIDE-GATED ION CHANNEL 14 and 16 promote tolerance to heat and chilling in rice. Plant Physiology: pp.00591.02020.

Chini, A., Fonseca, S., Fernández, G., Adie, B., Chico, J., Lorenzo, O., et al. (2007) The JAZ family of repressors is the missing link in jasmonate signalling. Nature 448: 666-671.

Chu, J. and Chen, Z. (2018) Molecular identification of histone acetyltransferases and deacetylases in lower plant Marchantia polymorpha. Plant Physiology and Biochemistry 132.

Dat, J., López-Delgado, H., Foyer, C. and Scott, I. (1998) Parallel Changes in H2O2 and Catalase during Thermotolerance Induced by Salicylic Acid or Heat Acclimation in Mustard Seedlings. Plant physiology 116: 1351-1357.

Danilova, M.N., Kudryakova, N.V., Andreeva, A.A., Doroshenko, A.S., Pojidaeva, E.S. and Kusnetsov, V.V. (2018) Differential impact of heat stress on the expression of chloroplast-encoded genes. Plant Physiology and Biochemistry 129: 90-100.

Davletova, S., Rizhsky, L., Liang, H., Shengqiang, Z., Oliver, D.J., Coutu, J., et al. (2005) Cytosolic ascorbate peroxidase 1 is a central component of the reactive oxygen gene network of Arabidopsis. Plant Cell 17: 268-281.

This article is protected by copyright. All rights reserved. 
de Sousa, F., Foster, P.G., Donoghue, P.C., Schneider, H. and Cox, C.J. (2019) Nuclear protein phylogenies support the monophyly of the three bryophyte groups (Bryophyta Schimp.). New Phytologist 222: 565-575.

de Vries, J., Curtis, B.A., Gould, S.B. and Archibald, J.M. (2018) Embryophyte stress signaling evolved in the algal progenitors of land plants. Proceedings of the National Academy of Sciences of the United States of America 115: E3471-E3480.

de Vries, J., de Vries, S., Curtis, B.A., Zhou, H., Penny, S., Feussner, K., et al. (2020) Heat stress response in the closest algal relatives of land plants reveals conserved stress signaling circuits. The Plant Journal.

DeFalco, T., Moeder, W. and Yoshioka, K. (2016) Opening the Gates: Insights into Cyclic NucleotideGated Channel-Mediated Signaling. Trends in plant science 21.

Devireddy, A.R., Arbogast, J. and Mittler, R. (2020) Coordinated and rapid whole-plant systemic stomatal responses. New Phytologist 225: 21-25.

Dietrich, P., Anschuetz, U., Kugler, A. and Becker, D. (2010) Physiology and biophysics of plant ligandgated ion channels. Plant biology (Stuttgart, Germany) 12 Suppl 1: 80-93.

Dickinson, P.J., Kumar, M., Martinho, C., Yoo, S.J., Lan, H., Artavanis, G., et al. (2018) Chloroplast Signaling Gates Thermotolerance in <em>Arabidopsis</em>. Cell Reports 22: 1657-1665.

Dietz, K.J., Mittler, R. and Noctor, G. (2016) Recent Progress in Understanding the Role of Reactive Oxygen Species in Plant Cell Signaling. Plant Physiol 171: 1535-1539. 
Eklund, D.M., Kanei, M., Flores-Sandoval, E., Ishizaki, K., Nishihama, R., Kohchi, T., et al. (2018) An evolutionarily conserved abscisic acid signaling pathway regulates dormancy in the liverwort Marchantia polymorpha. Current Biology 28: 3691-3699.

Elzanati, O., Mouzeyar, S. and Roche, J. (2020) Dynamics of the Transcriptome Response to Heat in the Moss, Physcomitrella patens. Int J Mol Sci 21: 1512.

Finka, A. and Goloubinoff, P. (2013) The CNGCb and CNGCd genes from Physcomitrella patens moss encode for thermosensory calcium channels responding to fluidity changes in the plasma membrane. Cell stress \& chaperones 19.

Finka, A., Mattoo, R.U. and Goloubinoff, P. (2011) Meta-analysis of heat- and chemically upregulated chaperone genes in plant and human cells. Cell Stress Chaperones 16: 15-31.

Flores-Sandoval, E., Dierschke, T., Fisher, T.J. and Bowman, J.L. (2015a) Efficient and Inducible Use of Artificial MicroRNAs in Marchantia polymorpha. Plant and Cell Physiology 57: 281-290.

Flores-Sandoval, E., Eklund, D.M. and Bowman, J.L. (2015b) A Simple Auxin Transcriptional Response System Regulates Multiple Morphogenetic Processes in the Liverwort Marchantia polymorpha. PLoS Genet 11: e1005207.

Flores-Sandoval, E., Eklund, D.M., Hong, S.-F., Alvarez, J., Fisher, T., Lampugnani, E., et al. (2018) Class C ARFs evolved before the origin of land plants and antagonize differentiation and developmental transitions in Marchantia polymorpha. New Phytologist 218.

Fonseca, S., Chico, J. and Solano, R. (2009) The jasmonate pathway: The ligand, the receptor and the core signalling module. Current opinion in plant biology 12: 539-547. 
Foyer, C.H., López-Delgado, H.A., Dat, J.F. and Scott, I.M. (1997) Hydrogen peroxide- and glutathioneassociated mechanisms of acclimatory stress tolerance and signalling.

Fujii, Y., Tanaka, H., Konno, N., Ogasawara, Y., Hamashima, N., Tamura, S., et al. (2017) Phototropin perceives temperature based on the lifetime of its photoactivated state. Proceedings of the National Academy of Sciences 114: 9206-9211.

Gil, K.-E. and Park, C.-M. (2019) Thermal adaptation and plasticity of the plant circadian clock. New Phytologist 221: 1215-1229.

Gil, K.E., Kim, W.Y., Lee, H.J., Faisal, M., Saquib, Q., Alatar, A.A., et al. (2017) ZEITLUPE Contributes to a Thermoresponsive Protein Quality Control System in Arabidopsis. The Plant cell 29: 2882-2894.

Gong, M., van der Luit, A., Knight, M. and Trewavas, A. (1998) Heat-Shock-Induced Changes in Intracellular Ca2+ Level in Tobacco Seedlings in Relation to Thermotolerance. Plant Physiology PLANT PHYSIOL 116: 429-437.

Hara, M., Shinoda, Y., Kubo, M., Kashima, D., Takahashi, I., Kato, T., et al. (2011) Biochemical characterization of the Arabidopsis KS-type dehydrin protein, whose gene expression is constitutively abundant rather than stress dependent. Acta Physiologiae Plantarum - ACTA PHYSIOL PLANT 33.

Harris, B.J., Harrison, C.J., Hetherington, A.M. and Williams, T.A. (2020) Phylogenomic evidence for the monophyly of bryophytes and the reductive evolution of stomata. Current Biology.

Haworth, M., Marino, G., Brunetti, C., Killi, D., De Carlo, A. and Centritto, M. (2018) The impact of heat stress and water deficit on the photosynthetic and stomatal physiology of olive (Olea europaea L.)-A case study of the 2017 heat wave. Plants 7: 76. 
Hirakawa, Y., Uchida, N., Yamaguchi, Y.L., Tabata, R., Ishida, S., Ishizaki, K., et al. (2019) Control of proliferation in the haploid meristem by CLE peptide signaling in Marchantia polymorpha. PLoS genetics 15: e1007997.

Hou, Q., Ufer, G. and Bartels, D. (2016) Lipid signalling in plant responses to abiotic stress. Plant, cell \& environment 39: 1029-1048.

Hua, J. (2009) From freezing to scorching, transcriptional responses to temperature variations in plants. Current opinion in plant biology 12: 568-573.

Huang, Y.-C., Niu, C.-Y., Yang, C.-R. and Jinn, T.-L. (2016) The Heat Stress Factor HSFA6b Connects ABA Signaling and ABA-Mediated Heat Responses. Plant Physiology 172: 1182.

Iba, K. (2002) Acclimative response to temperature stress in higher plants: Approaches of gene engineering for temperature tolerance. Annual review of plant biology 53: 225-245.

Islam, M., Baohua, F., Chen, T., Fu, W., Zhang, C., Tao, L., et al. (2018) Abscisic acid prevents pollen abortion under high temperature stress by mediating sugar metabolism in rice spikelets. Physiologia Plantarum 165.

Ivanov, A.G., Velitchkova, M.Y., Allakhverdiev, S.I. and Huner, N.P.A. (2017) Heat stress-induced effects of photosystem I: an overview of structural and functional responses. Photosynthesis research 133: $17-30$.

Jacob, P., Hirt, H. and Bendahmane, A. (2017) The heat-shock protein/chaperone network and multiple stress resistance. Plant Biotechnol J 15: 405-414. 
Jahan, A., Komatsu, K., Wakida-Sekiya, M., Hiraide, M., Tanaka, K., Ohtake, R., et al. (2019) Archetypal Roles of an Abscisic Acid Receptor in Drought and Sugar Responses in Liverworts. Plant Physiol 179: 317-328.

Jaimes-Miranda, F. and Montes, R. (2020) The plant MBF1 protein family: a bridge between stress and transcription. Journal of experimental botany 71.

Jung, C.G., Hwang, S.G., Park, Y.C., Park, H.M., Kim, D.S., Park, D.H., et al. (2015) Molecular characterization of the cold- and heat-induced Arabidopsis PXL1 gene and its potential role in transduction pathways under temperature fluctuations. Journal of plant physiology 176: 138146.

Kadota, Y., Shirasu, K. and Zipfel, C. (2015) Regulation of the NADPH oxidase RBOHD during plant immunity. Plant \& cell physiology 56.

Kanazawa, T., Ishizaki, K., Kohchi, T., Hanaoka, M. and Tanaka, K. (2013) Characterization of Four Nuclear-Encoded Plastid RNA Polymerase Sigma Factor Genes in the Liverwort Marchantia polymorpha: Blue-Light- and Multiple Stress-Responsive SIG5 was Acquired Early in the Emergence of Terrestrial Plants. Plant \& cell physiology 54.

Kaplan, B., Sherman, T. and Fromm, H. (2007) Cyclic nucleotide-gated channels in plants. FEBS letters 581: 2237-2246.

Katano, K., Honda, K. and Suzuki, N. (2018) Integration between ROS Regulatory Systems and Other Signals in the Regulation of Various Types of Heat Responses in Plants. Int J Mol Sci 19.

Kato, H., Ishizaki, K., Kouno, M., Shirakawa, M., Bowman, J.L., Nishihama, R., et al. (2015) AuxinMediated Transcriptional System with a Minimal Set of Components Is Critical for 
Morphogenesis through the Life Cycle in Marchantia polymorpha. PLoS genetics 11: e1005084e1005084.

Katoh, K., Rozewicki, J. and Yamada, K.D. (2017) MAFFT online service: multiple sequence alignment, interactive sequence choice and visualization. Briefings in Bioinformatics 20: 1160-1166.

Kim, S., Hwang, G., Kim, S., Thi, T.N., Kim, H., Jeong, J., et al. (2020) The epidermis coordinates thermoresponsive growth through the phyB-PIF4-auxin pathway. Nature communications 11: 1053.

Kim, T.-S., Kim, W.Y., Fujiwara, S., Kim, J., Cha, J.-Y., Park, J.H., et al. (2011) HSP90 functions in the circadian clock through stabilization of the client F-box protein ZEITLUPE. Proceedings of the National Academy of Sciences of the United States of America 108: 16843-16848.

Kimura, S., Hunter, K., Vaahtera, L., Tran, H.C., Citterico, M., Vaattovaara, A., et al. (2020) CRK2 and Cterminal Phosphorylation of NADPH Oxidase RBOHD Regulate Reactive Oxygen Species Production in Arabidopsis. The Plant cell 32: 1063-1080.

Komatsu, A., Terai, M., Ishizaki, K., Suetsugu, N., Tsuboi, H., Nishihama, R., et al. (2014) Phototropin encoded by a single-copy gene mediates chloroplast photorelocation movements in the liverwort Marchantia polymorpha. Plant physiology 166: 411-427.

Koskull-Döring, P., Scharf, K.-D. and Nover, L. (2007) The diversity of plant heat stress transcription factors. Trends in plant science 12: 452-457.

Kostaki, K.-I., Coupel-Ledru, A., Bonnell, V.C., Gustavsson, M., Sun, P., McLaughlin, F.J., et al. (2020) Guard Cells Integrate Light and Temperature Signals to Control Stomatal Aperture. Plant physiology 182: 1404-1419.

This article is protected by copyright. All rights reserved. 
Krishna, P. and Gloor, G. (2001) The Hsp90 family of proteins in Arabidopsis thaliana. Cell stress \& chaperones 6: 238-246.

Kruszka, K., Pacak, A., Swida-Barteczka, A., Nuc, P., Alaba, S., Wroblewska, Z., et al. (2014) Transcriptionally and post-transcriptionally regulated microRNAs in heat stress response in barley. J Exp Bot 65: 6123-6135.

Kubota, A., Kita, S., Ishizaki, K., Nishihama, R., Yamato, K.T. and Kohchi, T. (2014) Co-option of a photoperiodic growth-phase transition system during land plant evolution. Nature Communications 5: 3668.

Lamers, J., van der Meer, T. and Testerink, C. (2020) How Plants Sense and Respond to Stressful Environments. Plant Physiology 182: 1624-1635.

Larkindale, J. and Vierling, E. (2008) Core Genome Responses Involved in Acclimation to High Temperature. Plant physiology 146: 748-761.

Legris, M., Klose, C., Burgie, E.S., Rojas, C.C., Neme, M., Hiltbrunner, A., et al. (2016) Phytochrome B integrates light and temperature signals in Arabidopsis. Science (New York, N.Y.) 354: 897-900.

Li, B., Gao, K., Ren, H. and Tang, W. (2018) Molecular mechanisms governing plant responses to high temperatures. Journal of Integrative Plant Biology 60.

Li, H., Liu, S.S., Yi, C.Y., Wang, F., Zhou, J., Xia, X.J., et al. (2014) Hydrogen peroxide mediates abscisic acid-induced HSP70 accumulation and heat tolerance in grafted cucumber plants. Plant, cell \& environment 37: 2768-2780.

Li, S., Fu, Q., Huang, W. and Yu, D. (2009) Functional analysis of an Arabidopsis transcription factor WRKY25 in heat stress. Plant cell reports 28: 683-693. 
Lin, P.C., Lu, C.W., Shen, B.N., Lee, G.Z., Bowman, J.L., Arteaga-Vazquez, M.A., et al. (2016) Identification of miRNAs and Their Targets in the Liverwort Marchantia polymorpha by Integrating RNA-Seq and Degradome Analyses. Plant \& cell physiology 57: 339-358.

Lind, C., Dreyer, I., López-Sanjurjo, E., Meyer, K., Ishizaki, K., Kohchi, T., et al. (2015) Stomatal Guard Cells Co-opted an Ancient ABA-Dependent Desiccation Survival System to Regulate Stomatal Closure. Current Biology 25.

Liu, B., Hu, J. and Zhang, J. (2019a) Evolutionary Divergence of Duplicated Hsf Genes in Populus. Cells 8.

Liu, H., Gao, F., Cui, S., Han, J., Sun, D. and Zhou, R. (2006) Primary evidence for involvement of IP3 in heat-shock signal transduction in Arabidopsis. Cell research 16: 394-400.

Liu, J., Feng, L., Gu, X., Deng, X., Qiu, Q., Li, Q., et al. (2019b) An H3K27me3 demethylase-HSFA2 regulatory loop orchestrates transgenerational thermomemory in Arabidopsis. Cell Research 29: 379-390.

Liu, J., Feng, L., Li, J. and He, Z. (2015) Genetic and epigenetic control of plant heat responses. Front Plant Sci 6: 267.

Liu, J., Zhang, C., Wei, C., Liu, X., Wang, M., Yu, F., et al. (2016) The RING finger ubiquitin E3 ligase OsHTAS enhances heat tolerance by promoting H2O2-induced stomatal closure in rice. Plant Physiology 170: 429-443.

Mäser, P. (2001) Phylogenetic Relationships within Cation Transporter Families of Arabidopsis. PLANT PHYSIOLOGY 126: 1646-1667. 
Mathur, S., Agrawal, D. and Jajoo, A. (2014) Photosynthesis: response to high temperature stress. Journal of photochemistry and photobiology. B, Biology 137: 116-126.

Mhamdi, A. and Van Breusegem, F. (2018) Reactive oxygen species in plant development. Development 145: dev164376.

Miller, G., Schlauch, K., Tam, R., Cortes, D., Torres, M.A., Shulaev, V., et al. (2009) The plant NADPH oxidase RBOHD mediates rapid systemic signaling in response to diverse stimuli. Science signaling 2: ra45.

Miller, G., Suzuki, N., Rizhsky, L., Hegie, A., Koussevitzky, S. and Mittler, R. (2007) Double mutants deficient in cytosolic and thylakoid ascorbate peroxidase reveal a complex mode of interaction between reactive oxygen species, plant development, and response to abiotic stresses. Plant Physiol 144: 1777-1785.

Mittler, R., Finka, A. and Goloubinoff, P. (2012) How do plants feel the heat? Trends Biochem Sci. Trends in Biochemical Sciences 37.

Mittler, R., Vanderauwera, S., Gollery, M. and Van Breusegem, F. (2004) Reactive oxygen gene network of plants [J]. Trends Plant Sci. 9: 1360-1385.

Moeder, W., Urquhart, W., Ung, H. and Yoshioka, K. (2011) The Role of Cyclic Nucleotide-Gated Ion Channels in Plant Immunity. Molecular plant 4: 442-452.

Monte, I., Franco-Zorrilla, J., García-Casado, G., Zamarreño, A., Garcia-Mina, J., Nishihama, R., et al. (2018a) A Single JAZ Repressor Controls the Jasmonate Pathway in Marchantia polymorpha. Molecular Plant 12.

This article is protected by copyright. All rights reserved. 
Monte, I., Ishida, S., Zamarreño, A., Hamberg, M., Franco-Zorrilla, J., García-Casado, G., et al. (2018b) Ligand-receptor co-evolution shaped the jasmonate pathway in land plants. Nature chemical biology 14.

Monte, I., Kneeshaw, S., Franco-Zorrilla, J.M., Chini, A., Zamarreno, A.M., Garcia-Mina, J.M., et al. (2020) An Ancient COI1-Independent Function for Reactive Electrophilic Oxylipins in Thermotolerance. Current biology : CB 30: 962-971 e963.

Montgomery, S.A., Tanizawa, Y., Galik, B., Wang, N., Ito, T., Mochizuki, T., et al. (2020) Chromatin Organization in Early Land Plants Reveals an Ancestral Association between H3K27me3, Transposons, and Constitutive Heterochromatin. Current biology : CB 30: 573-588 e577.

Morris, J.L., Puttick, M.N., Clark, J.W., Edwards, D., Kenrick, P., Pressel, S., et al. (2018) The timescale of early land plant evolution. Proceedings of the National Academy of Sciences 115: E2274-E2283.

Muench, M., Hsin, C.H., Ferber, E., Berger, S. and Mueller, M.J. (2016) Reactive electrophilic oxylipins trigger a heat stress-like response through HSFA1 transcription factors. Journal of experimental botany 67: 6139-6148.

Nishihama, R., Ishida, S., Urawa, H., Kamei, Y. and Kohchi, T. (2016) Conditional Gene Expression/Deletion Systems for Marchantia polymorpha Using its Own Heat-Shock Promoter and Cre/loxP-Mediated Site-Specific Recombination. Plant \& cell physiology 57: 271-280.

Ohama, N., Sato, H., Shinozaki, K. and Yamaguchi-Shinozaki, K. (2017) Transcriptional Regulatory Network of Plant Heat Stress Response. Trends Plant Sci 22: 53-65.

This article is protected by copyright. All rights reserved. 
Oshino, T., Miura, S., Kikuchi, S., Hamada, K., Yano, K., Watanabe, M., et al. (2011) Auxin depletion in barley plants under high-temperature conditions represses DNA proliferation in organelles and nuclei via transcriptional alterations. Plant Cell Environ 34: 284-290.

Park, S., Moon, J.C., Park, Y.C., Kim, J.H., Kim, D.S. and Jang, C.S. (2014) Molecular dissection of the response of a rice leucine-rich repeat receptor-like kinase (LRR-RLK) gene to abiotic stresses. Journal of plant physiology 171: 1645-1653.

Popova, O., Dinh, H., Aufsatz, W. and Jonak, C. (2013) The RdDM Pathway Is Required for Basal Heat Tolerance in Arabidopsis. Molecular plant 6.

Puttick, M.N., Morris, J.L., Williams, T.A., Cox, C.J., Edwards, D., Kenrick, P., et al. (2018) The interrelationships of land plants and the nature of the ancestral embryophyte. Current Biology 28: 733-745. e732.

Qi, Y., Sun, Y., Xu, L., Xu, Y. and Huang, H. (2004) ERECTA is required for protection against heat-stress in the AS1/ AS2 pathway to regulate adaxial-abaxial leaf polarity in Arabidopsis. Planta 219: 270276.

Ruibal, C., Castro, A., Carballo, V., Szabados, L. and Vidal, S. (2013) Recovery from heat, salt and osmotic stress in Physcomitrella patens requires a functional small heat shock protein PpHsp16.4. BMC plant biology 13: 174 .

Sagi, M. and Fluhr, R. (2001) Superoxide production by plant homologues of the gp91(phox) NADPH oxidase. Modulation of activity by calcium and by tobacco mosaic virus infection. Plant Physiol 126: $1281-1290$. 
Saidi, Y., Finka, A., Chakhporanian, M., Zrÿd, J.P., Schaefer, D.G. and Goloubinoff, P. (2005) Controlled expression of recombinant proteins in Physcomitrella patens by a conditional heat-shock promoter: a tool for plant research and biotechnology. Plant Mol Biol 59: 697-711.

Saidi, Y., Finka, A. and Goloubinoff, P. (2010) Heat perception and signalling in plants: A tortuous path to thermotolerance. The New phytologist 190: 556-565.

Saidi, Y., Finka, A., Muriset, M., Bromberg, Z., Weiss, Y., Maathuis, F., et al. (2009) The Heat Shock Response in Moss Plants Is Regulated by Specific Calcium-Permeable Channels in the Plasma Membrane. The Plant cell 21: 2829-2843.

Sajid, M., Rashid, B., Ali, Q. and Husnain, T. (2018) Mechanisms of heat sensing and responses in plants. It is not all about Ca2+ ions. Biologia Plantarum 62: 409-420.

Schippers, J.H., Foyer, C.H. and van Dongen, J.T. (2016) Redox regulation in shoot growth, SAM maintenance and flowering. Current opinion in plant biology 29: 121-128.

Sharma, N., Jung, C.-H., Bhalla, P.L. and Singh, M.B. (2014) RNA sequencing analysis of the gametophyte transcriptome from the liverwort, Marchantia polymorpha. PLoS One 9: e97497-e97497.

Sheard, L.B., Tan, X., Mao, H., Withers, J., Ben-Nissan, G., Hinds, T.R., et al. (2010) Jasmonate perception by inositol-phosphate-potentiated COI1-JAZ co-receptor. Nature 468: 400-405.

Shen, H., Zhu, L., Castillon, A., Majee, M., Downie, B. and Huq, E. (2008) Light-induced phosphorylation and degradation of the negative regulator PHYTOCHROME-INTERACTING FACTOR1 from Arabidopsis depend upon its direct physical interactions with photoactivated phytochromes. The Plant cell 20: 1586-1602.

This article is protected by copyright. All rights reserved. 
Shimamura, M. (2016) Marchantia polymorpha: taxonomy, phylogeny and morphology of a model system. Plant and Cell Physiology 57: 230-256.

Smith, S.T., Petruk, S., Sedkov, Y., Cho, E., Tillib, S., Canaani, E., et al. (2004) Modulation of heat shock gene expression by the TAC1 chromatin-modifying complex. Nature cell biology 6: 162-167.

Sousa, F., Civáň, P., Foster, P.G. and Cox, C.J. (2020) The chloroplast land plant phylogeny: analyses employing better-fitting tree-and site-heterogeneous composition models. Frontiers in plant science 11: 1062.

Stumpe, M., Göbel, C., Faltin, B., Ostendorf geb. Beike, A., Hause, B., Himmelsbach, K., et al. (2010) The moss Physcomitrella patens contains cyclopentenones but no jasmonates: Mutations in allene oxide cyclase lead to reduced fertility and altered sporophyte morphology. The New phytologist 188: $740-749$.

Sun, Y., Harpazi, B., Wijerathna-Yapa, A., Merilo, E., de Vries, J., Michaeli, D., et al. (2019) A ligandindependent origin of abscisic acid perception. Proceedings of the National Academy of Sciences 116: 24892-24899.

Sunkar, R., Li, Y.-F. and Jagadeeswaran, G. (2012) Functions of microRNAs in plant stress responses. Trends in plant science 17: 196-203.

Suzuki, N., Bajad, S., Shuman, J., Shulaev, V. and Mittler, R. (2008) The Transcriptional Co-activator MBF1c Is a Key Regulator of Thermotolerance in Arabidopsis thaliana. The Journal of biological chemistry 283: 9269-9275.

Suzuki, N., Koussevitzky, S., Mittler, R. and Miller, G. (2011) ROS and redox signaling in the response of plants to abiotic stress. Plant, cell \& environment 35: 259-270. 
Suzuki, N., Miller, G., Salazar, C., Mondal, H.A., Shulaev, E., Cortes, D.F., et al. (2013) Temporal-Spatial Interaction between Reactive Oxygen Species and Abscisic Acid Regulates Rapid Systemic Acclimation in Plants. The Plant cell 25: 3553.

Swindell, W.R., Huebner, M. and Weber, A.P. (2007) Transcriptional profiling of Arabidopsis heat shock proteins and transcription factors reveals extensive overlap between heat and non-heat stress response pathways. BMC Genomics 8: 125.

Talke, I., Blaudez, D., Maathuis, F. and Sanders, D. (2003) CNGCs: Prime targets of plant cyclic nucleotide signaling. Trends in plant science 8: 286-293.

Tang, T., Yu, A., Li, P., Yang, H., Liu, G. and Liu, L. (2016) Sequence analysis of the Hsp70 family in moss and evaluation of their functions in abiotic stress responses. Scientific reports 6: 33650.

Török, Z., Crul, T., Maresca, B., Schütz, G.J., Viana, F., Dindia, L., et al. (2014) Plasma membranes as heat stress sensors: from lipid-controlled molecular switches to therapeutic applications. Biochim Biophys Acta 1838: 1594-1618.

Torres, M.A. and Dangl, J. (2005) Functions of the respiratory burst oxidase in biotic interactions, abiotic stress and development. Current opinion in plant biology 8: 397-403.

Torres, M.A., Onouchi, H., Hamada, S., Machida, C., Hammond-Kosack, K.E. and Jones, J.D. (1998) Six Arabidopsis thaliana homologues of the human respiratory burst oxidase (gp91phox). The Plant journal : for cell and molecular biology 14: 365-370.

Tougane, K., Komatsu, K., Bhyan, S.B., Sakata, Y., Ishizaki, K., Yamato, K.T., et al. (2010) Evolutionarily Conserved Regulatory Mechanisms of Abscisic Acid Signaling in Land Plants: Characterization of 
\&lt;em\&gt;ABSCISIC ACID INSENSITIVE1\&It;/em\&gt;-Like Type 2C Protein Phosphatase in the Liverwort \&lt;em\&gt;Marchantia polymorpha\&lt;/em\&gt. Plant Physiology 152: 1529.

Trifinopoulos, J., Nguyen, L.-T., von Haeseler, A. and Minh, B.Q. (2016) W-IQ-TREE: a fast online phylogenetic tool for maximum likelihood analysis. Nucleic Acids Research 44: W232-W235.

Tsuda, K. and Yamazaki, K. (2004) Structure and expression analysis of three subtypes of Arabidopsis MBF1 genes. Biochim Biophys Acta 1680: 1-10.

Vu, L., Gevaert, K. and Smet, I. (2018) Feeling the Heat: Searching for Plant Thermosensors. Trends in Plant Science 24.

Wang, C.-T. and Song, W. (2014) ZmCK3, a maize calcium-dependent protein kinase gene, endows tolerance to drought and heat stresses in transgenic Arabidopsis. Journal of Plant Biochemistry and Biotechnology 23.

Wang, D., Heckathorn, S.A., Mainali, K. and Tripathee, R. (2016) Timing Effects of Heat-Stress on Plant Ecophysiological Characteristics and Growth. Frontiers in Plant Science 7.

Wang, X., Zhuang, L., Shi, Y. and Huang, B. (2017) Up-Regulation of HSFA2c and HSPs by ABA Contributing to Improved Heat Tolerance in Tall Fescue and Arabidopsis. Int J Mol Sci 18: 1981.

Waszczak, C., Kerchev, P.I., Mühlenbock, P., Hoeberichts, F.A., Van Der Kelen, K., Mhamdi, A., et al. (2016) SHORT-ROOT Deficiency Alleviates the Cell Death Phenotype of the Arabidopsis catalase2 Mutant under Photorespiration-Promoting Conditions. The Plant cell 28: 1844-1859.

Wen, F., Xing, D. and Zhang, L. (2008) Hydrogen peroxide is involved in high blue light-induced chloroplast avoidance movements in Arabidopsis. Journal of Experimental Botany 59: 28912901. 
Wu, H.-C. and Jinn, T.-L. (2010) Ethylesterase activity and cytosolic Ca2+ oscillation are crucial for plant thermotolerance. Plant signaling \& behavior 5: 1252-1256.

Wu, T., Tian, Z., Liu, J. and Xie, C. (2009) A novel leucine-rich repeat receptor-like kinase gene in potato, StLRPK1, is involved in response to diverse stresses. Molecular biology reports 36: 2365-2374.

Xue-Franzén, Y., Henriksson, J., Bürglin, T.R. and Wright, A.P. (2013) Distinct roles of the Gcn5 histone acetyltransferase revealed during transient stress-induced reprogramming of the genome. $B M C$ Genomics 14: 479.

Yamada, K., Fukao, Y., Hayashi, M., Fukazawa, M., Suzuki, I. and Nishimura, M. (2007) Cytosolic HSP90 regulates the heat shock response that is responsible for heat acclimation in Arabidopsis thaliana. The Journal of biological chemistry 282: 37794-37804.

Yu, H.-D., Yang, X.-F., Chen, S.-T., Wang, Y.-T., Li, J.-K., Shen, Q., et al. (2012) Downregulation of Chloroplast RPS1 Negatively Modulates Nuclear Heat-Responsive Expression of HsfA2 and Its Target Genes in Arabidopsis. PLOS Genetics 8: e1002669.

Zandalinas, S.I., Balfagón, D., Arbona, V., Gómez-Cadenas, A., Inupakutika, M.A. and Mittler, R. (2016) $A B A$ is required for the accumulation of APX1 and MBF1c during a combination of water deficit and heat stress. Journal of experimental botany 67: 5381-5390.

Zhang, J., Li, J., Liu, B., Zhang, L., Chen, J. and Lu, M. (2013) Genome-wide analysis of the Populus Hsp90 gene family reveals differential expression patterns, localization, and heat stress responses. BMC genomics 14: 532-532.

This article is protected by copyright. All rights reserved. 
Zhang, L., Li, Y., Xing, D. and Gao, C. (2009) Characterization of mitochondrial dynamics and subcellular localization of ROS reveal that HsfA2 alleviates oxidative damage caused by heat stress in Arabidopsis. Journal of experimental botany 60: 2073-2091.

Zhang, Q., Kong, X., Yu, Q., Ding, Y., Li, X. and Yang, Y. (2019a) Responses of PYR/PYL/RCAR ABA Receptors to Contrasting stresses, Heat and Cold in Arabidopsis. Plant Signal Behav 14: 1670596.

Zhang, X., Wang, X., Zhuang, L., Gao, Y. and Huang, B. (2019b) Abscisic acid mediation of drought priming-enhanced heat tolerance in tall fescue (Festuca arundinacea) and Arabidopsis. Physiologia Plantarum 167.

Zhang, J., Fu, X.-X., Li, R.-Q., Zhao, X., Liu, Y., Li, M.-H., et al. (2020) The hornwort genome and early land plant evolution. Nature plants 6: 107-118.

Zhao, C., Wang, Y., Chan, K.X., Marchant, D.B., Franks, P.J., Randall, D., et al. (2019) Evolution of chloroplast retrograde signaling facilitates green plant adaptation to land. Proceedings of the National Academy of Sciences 116: 5015-5020.

Zhao, P., Cui, R., Xu, P., Wu, J., Mao, J.-L., Chen, Y., et al. (2017) ATHB17 enhances stress tolerance by coordinating photosynthesis associated nuclear gene and ATSIG5 expression in response to abiotic stress. Scientific reports 7: DOI: 10.1038/srep45492.

Zhu, Y., Tepperman, J.M., Fairchild, C.D. and Quail, P.H. (2000) Phytochrome B binds with greater apparent affinity than phytochrome A to the basic helix-loop-helix factor PIF3 in a reaction requiring the PAS domain of PIF3. Proceedings of the National Academy of Sciences of the United States of America 97: 13419-13424.

This article is protected by copyright. All rights reserved. 
Table1. HSPs and HSFs present in Marchantia polymorpha showing their corresponding homolog in Arabidopsis

\begin{tabular}{|c|c|c|c|}
\hline Transcript ID & KEGG Pathway & Mapoly ID & $\begin{array}{l}\text { A.thaliana } \\
\text { closest } \\
\text { homologue }\end{array}$ \\
\hline \multicolumn{4}{|l|}{ MpHSP90s } \\
\hline Mp1g26610.1 & $\begin{array}{l}\text { HSP90A, htpG; molecular chaperone } \\
\text { HtpG }\end{array}$ & $\begin{array}{l}\text { Mapoly0002s021 } \\
7.1\end{array}$ & HSP90.4 \\
\hline Mp4g19750.1 & $\begin{array}{l}\text { HSP90A, htpG; molecular chaperone } \\
\text { HtpG }\end{array}$ & $\begin{array}{l}\text { Mapoly0126s001 } \\
9.1\end{array}$ & HSP90.4 \\
\hline Mp5g15940.1 & $\begin{array}{l}\text { HSP90B, TRA1; heat shock protein } \\
\text { 90kDa beta }\end{array}$ & $\begin{array}{l}\text { Mapoly0071s001 } \\
6.1\end{array}$ & HSP90.5 \\
\hline Mp6g06660.1 & $\begin{array}{l}\text { HSP90A, htpG; molecular chaperone } \\
\text { HtpG }\end{array}$ & $\begin{array}{l}\text { Mapoly0173s001 } \\
1.1\end{array}$ & HSP90.1 \\
\hline Mp2g04900.1 & $\begin{array}{l}\text { HSP90B, TRA1; heat shock protein } \\
\text { 90kDa beta }\end{array}$ & $\begin{array}{l}\text { Mapoly0031s014 } \\
5.1\end{array}$ & HSP90.7 \\
\hline \multicolumn{4}{|l|}{ MpHSP70s } \\
\hline Mp4g11410.1 & $\begin{array}{l}\text { HSPA1s; heat shock } 70 k \text { Da protein } \\
1 / 2 / 6 / 8\end{array}$ & $\begin{array}{l}\text { Mapoly0011s012 } \\
5.1\end{array}$ & HSP70.1 \\
\hline Mp2g04890.1 & $\begin{array}{l}\text { HSPA5, BIP; heat shock 70kDa protein } \\
5\end{array}$ & $\begin{array}{l}\text { Mapoly0031s014 } \\
4.1\end{array}$ & BIP2 \\
\hline Mp2g08350.1 & $\begin{array}{l}\text { HSPA1s; heat shock 70kDa protein } \\
1 / 2 / 6 / 8\end{array}$ & $\begin{array}{l}\text { Mapoly0015s012 } \\
0.1\end{array}$ & HSP70.1 \\
\hline Mp8g07330.1 & $\begin{array}{l}\text { dnaK, HSPA9; molecular chaperone } \\
\text { DnaK }\end{array}$ & $\begin{array}{l}\text { Mapoly0013s006 } \\
0.1\end{array}$ & MtHSP70.1 \\
\hline Mp8g13250.1 & $\begin{array}{l}\text { HSPA1s; heat shock 70kDa protein } \\
1 / 2 / 6 / 8\end{array}$ & $\begin{array}{l}\text { Mapoly0110s000 } \\
6.1\end{array}$ & CpHSP70.2 \\
\hline Mp8g13310.1 & $\begin{array}{l}\text { HSPA1s; heat shock } 70 \mathrm{kDa} \text { protein } \\
1 / 2 / 6 / 8\end{array}$ & $\begin{array}{l}\text { Mapoly0110s001 } \\
2.1\end{array}$ & CpHSP70.2 \\
\hline Mp3g22900.1 & Molecular chaperones & $\begin{array}{l}\text { Mapoly0024s006 } \\
7.1\end{array}$ & HSP70.3 \\
\hline Mp7g10010.1 & HYOU1; hypoxia up-regulated 1 & $\begin{array}{l}\text { Mapoly0003s002 } \\
0.1\end{array}$ & HSP70.17 \\
\hline Mp4g05820.1 & $\begin{array}{l}\text { Molecular chaperones } \\
\text { GRP78/BiP/KAR2, HSP70 superfamily; } \\
\text { C-term missing; [O] }\end{array}$ & $\begin{array}{l}\text { Mapoly0087s000 } \\
9.1\end{array}$ & HSP70.4 \\
\hline Mp6g10360.1 & $\begin{array}{l}\text { HSP110; heat shock protein } 110 \mathrm{kDa} \\
\text { PFAM HSP70 }\end{array}$ & $\begin{array}{l}\text { Mapoly0016s007 } \\
8.1\end{array}$ & HSP70.14/HSP91 \\
\hline Mp8g06490.1 & HSPA4; heat shock 70kDa protein 4 & $\begin{array}{l}\text { Mapoly0013s014 } \\
1.1\end{array}$ & HSP70.14/HSP91 \\
\hline \multicolumn{4}{|l|}{ HSFs } \\
\hline Mp4g12230 & HSFF; heat shock transcription factor, & Mapoly0011s020 & HSFB4/SCZ \\
\hline
\end{tabular}

This article is protected by copyright. All rights reserved. 


\begin{tabular}{lll} 
MpVg00470 & $\begin{array}{l}\text { other eukaryote } \\
\text { HSFF; heat shock transcription factor, MapolyY_B0005.1 HSF3/HSFA1B } \\
\text { other eukaryote }\end{array}$ & $\begin{array}{l}5.1 \\
\text { M }\end{array}$ \\
\hline
\end{tabular}

Tabl

HSPs and HSFs present in Marchantia polymorpha showing their corresponding homolog in Arabidopsis

This article is protected by copyright. All rights reserved. 


\section{Figure legends}

Figure 1. Phylogenetic analysis of CNGC proteins in M. polymorpha. A) Evolutionary relationship between land plant groups and their estimated appearance by molecular clock (Morris et al. 2018). B) CNGC protein sequences from $M$. polymorpha were collected from MarpolBASE database (https://marchantia.info/). Protein sequences were aligned using MAFFT 7 with the iterative refinement method E-INS-i (Katoh et al. 2017). Phylogenetic relationships were inferred based on maximum likelihood using IQ-TREE v2.0 with the substitution model Blosum 62 and empirical state frequencies (Trifinopoulos et al. 2016). Branch support values were obtained from 1000 replicates. The tree was edited using iTOL v5. The cluster "Group IVa” (red background) includes CNGC channels associated to heat stress response in Arabidopsis and Physcomitrium, and the CNGC proteins proposed to accomplish a similar function in Marchantia. C) Protein Domain Architecture of Group IVa CNGCs. Red boxes represent transmembrane domains. The green box shows the regulatory domain dependent on 
cNMP. Orange and Purple boxes show the position of regulatory domains associated to calmodulin regulation.

Figure 2. Proposed mechanisms for heat stress sensing in Marchantia. Changes in plasma membrane fluidity are associated with a specific transient $\mathrm{Ca}^{2+}$ influx through the plasma membrane-embedded Cyclic Nucleotide-gated $\mathrm{Ca}^{2+}$ Channels in angiosperms, a mechanism that might also take place in Marchantia through the conserved MpCNGCs. Leucine-rich repeat receptor-like protein kinases (LRR-RLKs such as MpERECTA and MpPXL1) are also proposed to act as heat sensors. In addition, PHOTOTROPIN (MpPHOT), which is the homolog of the Arabidopsis blue light receptors AtPHOT1 and AtPHOT2 and has been proposed as a thermosensor in Marchantia. Finally, chloroplasts might also play a role sensing high temperatures in a diurnal pattern and inducing a transcriptional response upon heat stress, resulting in acclimation as observed in A. thaliana.

Figure 3. Proposed mechanisms underlying ROS accumulation in response to heat stress in Marchantia. $\mathrm{Ca}^{2+}$ signaling has been linked to ROS production by plant NADPH oxidases/RBOHs, as they are activated by $\mathrm{Ca}^{2+}$ binding to their EF-hand motifs. MpPHOT might also play a role inducing an increase in cytoplasmic $\mathrm{Ca}^{2+}$ promoting $\mathrm{ROS}$ production via $\mathrm{RBOH}$ activation. Other important sources of ROS during heat stress in plants constitute the 
mitochondria and chloroplasts, which might also have a role in Marchantia. High levels of ROS induce a complex network of detoxifying enzymes, which generally mediate adaptive responses.

\section{Figure 4. Transcriptional responses during heat stress response in Marchantia.}

Responses to heat stress at the transcriptional level include the expression of a group of genes related to survival of the plant cell and to avoid the damages caused by high temperatures. Calcium influx triggered in response to heat induces the activation of MpHSFs proteins in the cytosol and induce MpHSFs and MpHSP17.8A1 gene expression in Marchantia. It is also predicted that several MpHSP 90/70 might be activated at specific subcellular compartments in response to heat stress, based on their homology with their Arabidopsis counterparts (Table 1). Inside the nucleus, MpHSF1 y MpHSF3 might act as key regulators of the heat stress response. It is proposed that MpMBF1c is translocated to the nucleus in a ROS-dependent manner, where it can regulate the expression of specific genes in response to heat stress (MpHSR). Full arrows indicate pathways experimentally proven while and dash arrows show putative pathways.

Figure 5. Involvement of phytohormones in the heat stress response in Marchantia. The jasmonic signaling response pathway is activated in Marchantia in response to high temperatures. The JA-L-ILE precursor dn-OPDA activates the expression of MpJA-R and MpHSR (heat stress-response genes) upon heat stress, increasing thermotolerance. ABA is also 
proposed as an actor in the heat stress response in Marchantia, as it induces MpHSFs through the canonical MpPyr-MpSNRK-MpAREB pathway. During heat stress, MpARFs are also induced via a proposed auxin-dependent mechanism. Full lines indicate experimentally proven paths, while dashed lines show putative proposed pathways that might be functional in Marchantia based on conserved heat stress-response genes.

Figure 6. Epigenetic response proposed during heat stress response in Marchantia. As the expression of Marchantia histone acetyltransferases (HATs) and histone deacetylases (HDACs) is induced upon heat stress, it is proposed that covalent histone modifications through acetylation or deacetylation by HATs or HDACs might also take place in the heat stress response. Plant response to heat stress also involves miRNA regulation. Since miR160 is induced by heat in vascular plants and its putative target in Marchantia, MpARF3, is suppressed during heat stress, a mechanism involving miRNA is also proposed. Full arrows indicate proven pathways of the hormonal heat stress response in Marchantia and dash arrows show putative pathways.

Figure 7. Proposed model for heat stress sensing and response in Marchantia. Early events include plasma membrane structure/composition modification and the activation of MpCNGC calcium channels. The subsequent increase in cytosolic Calcium $\left(\mathrm{Ca}^{+}\right)$concentration is proposed to activate a $\mathrm{Ca}^{2+}$-calmodulin (CaM) pathway that results in the activation of 
MpHSFs, inducing the expression of MpHSPs as observed in angiosperms. Leucine-rich repeat receptor-like protein kinases (LRR-RLKs such as MpERECTA and MpPXL1) are also proposed to act as heat sensors. An oxidative burst is also observed upon heat stress, which might result not only from MpRBOH activity, but also from mitochondrial and chloroplastic ROS. Jasmonates were also shown to play a role in the response to high temperatures. The JA-L-ILE precursor dn-OPDA is able to activate HSPs and antioxidant enzymes upon heat stress, increasing thermotolerance. In addition, Abscicic acid (ABA) is also proposed to play a role during the heat stress response activating HSPs. The canonical conserved signaling pathway in Marchantia is shown. Two epigenetic mechanisms might act in Marchantia to develop thermotolerance. The histone acetyl-deacetyltransferases (MpHAT and MpHDACs) are induced upon heat stress and MpMiR160 is proposed to regulate its target MpARF3. Dashed lines indicate proposed pathways based on the presence of conserved core proteins while full lines indicate experimentally demonstrated mechanisms. 
Sensing and response to high temperatures are crucial mechanisms to prevent heat-related damage and to preserve cellular functions. In this review we aim to provide an insight into the most recent advances in elucidating the mechanisms and pathways involved in the response to heat stress in the bryophyte Marchantia polymorpha. We discuss conserved and divergent pathways that relate temperature sensing with a plethora of transduction cascades that are emerging as central future research directions. 


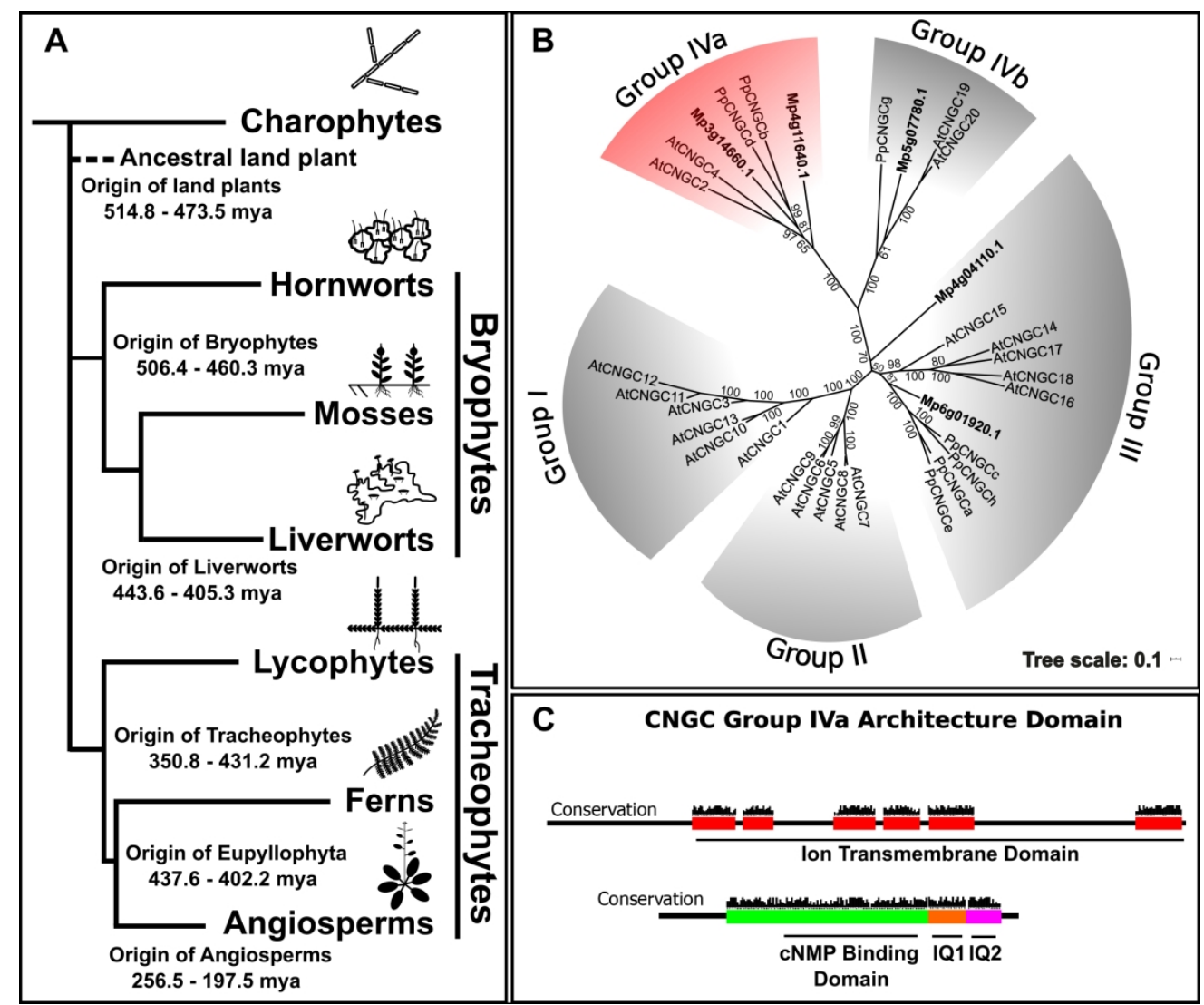

This article is protected by copyright. All rights reserved. 

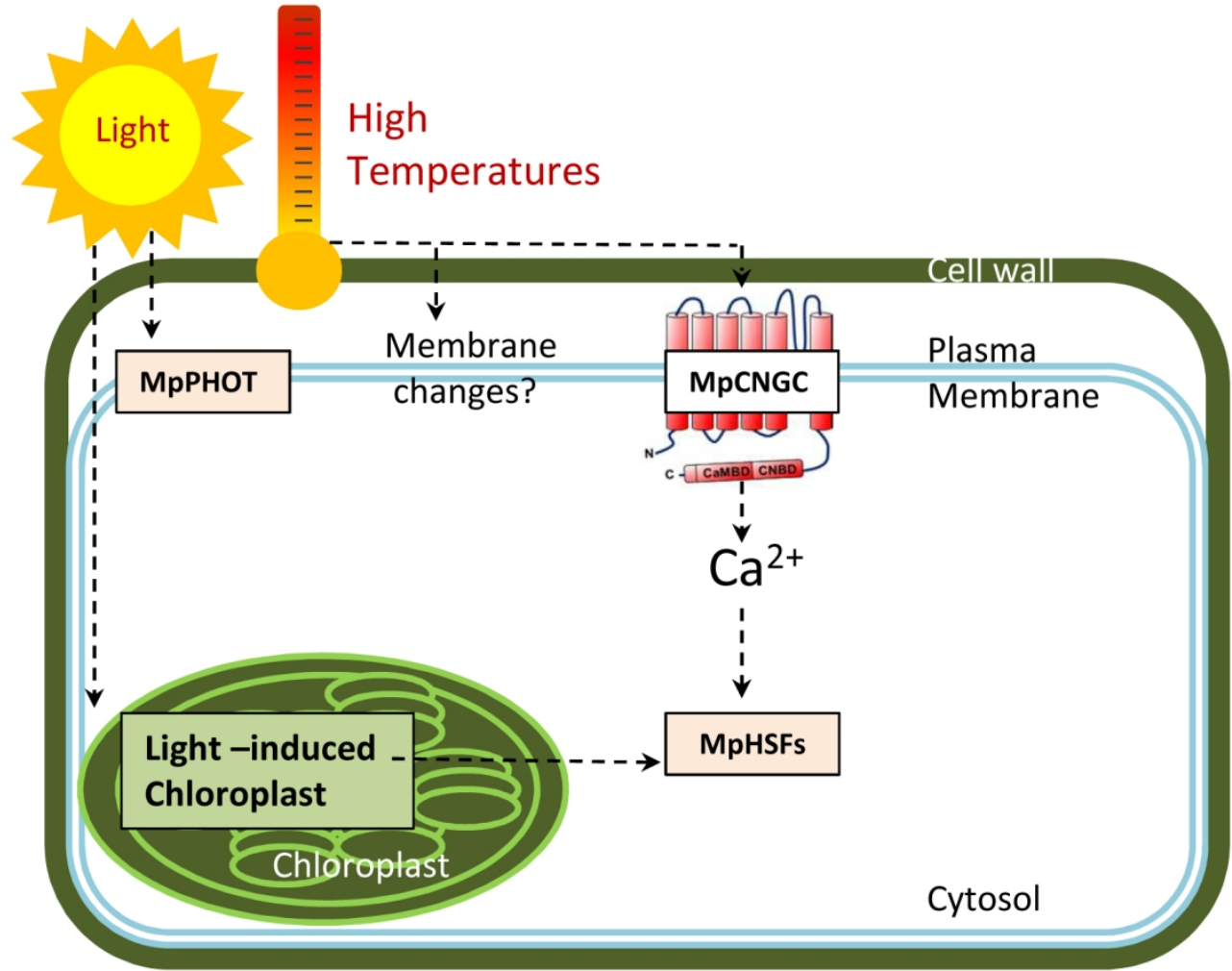

$\square$ Experimentally demonstrated in Physcomitrium and Arabidopsis

Putative component proposed in Marchantia

- - - Proposed pathway in Marchantia 


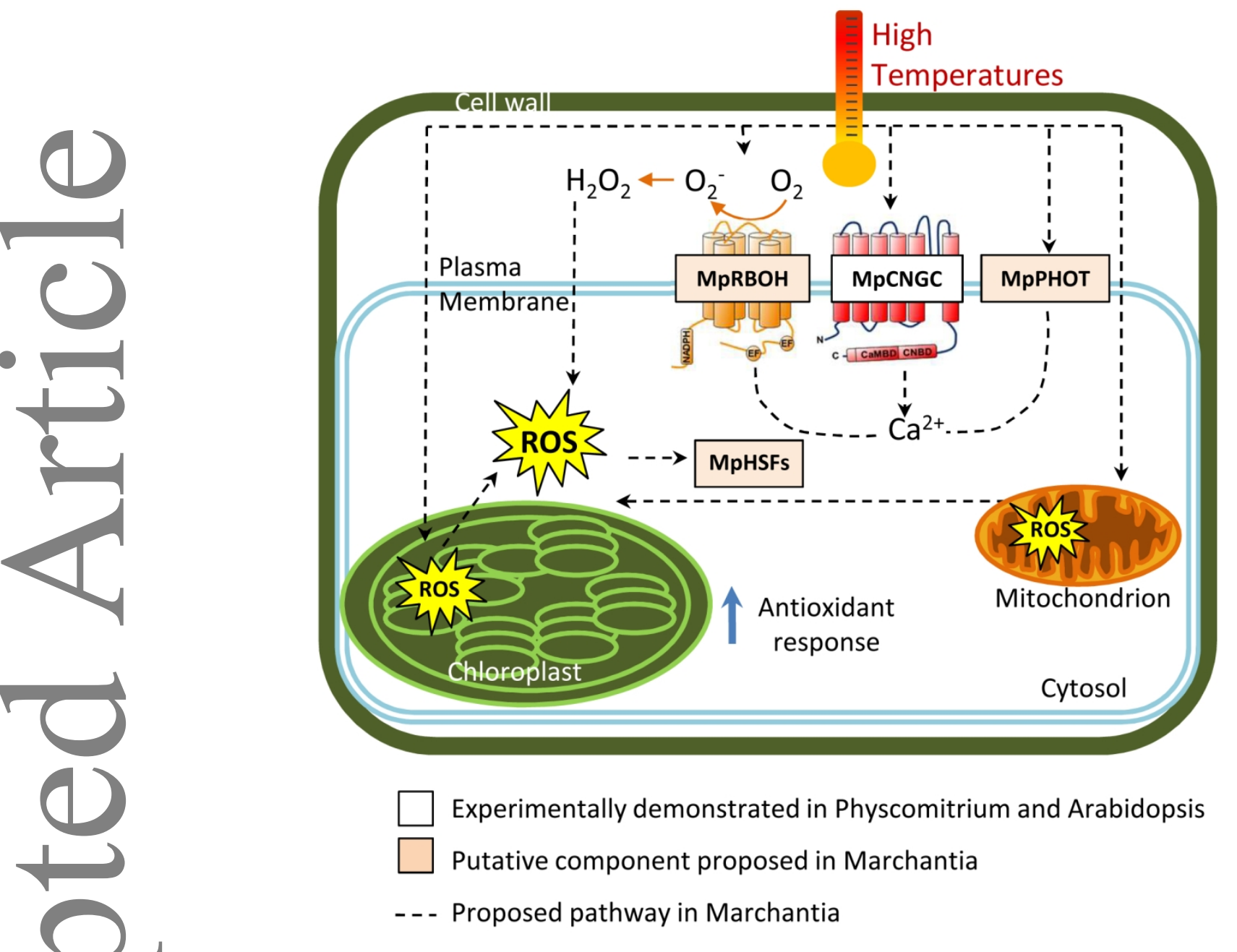



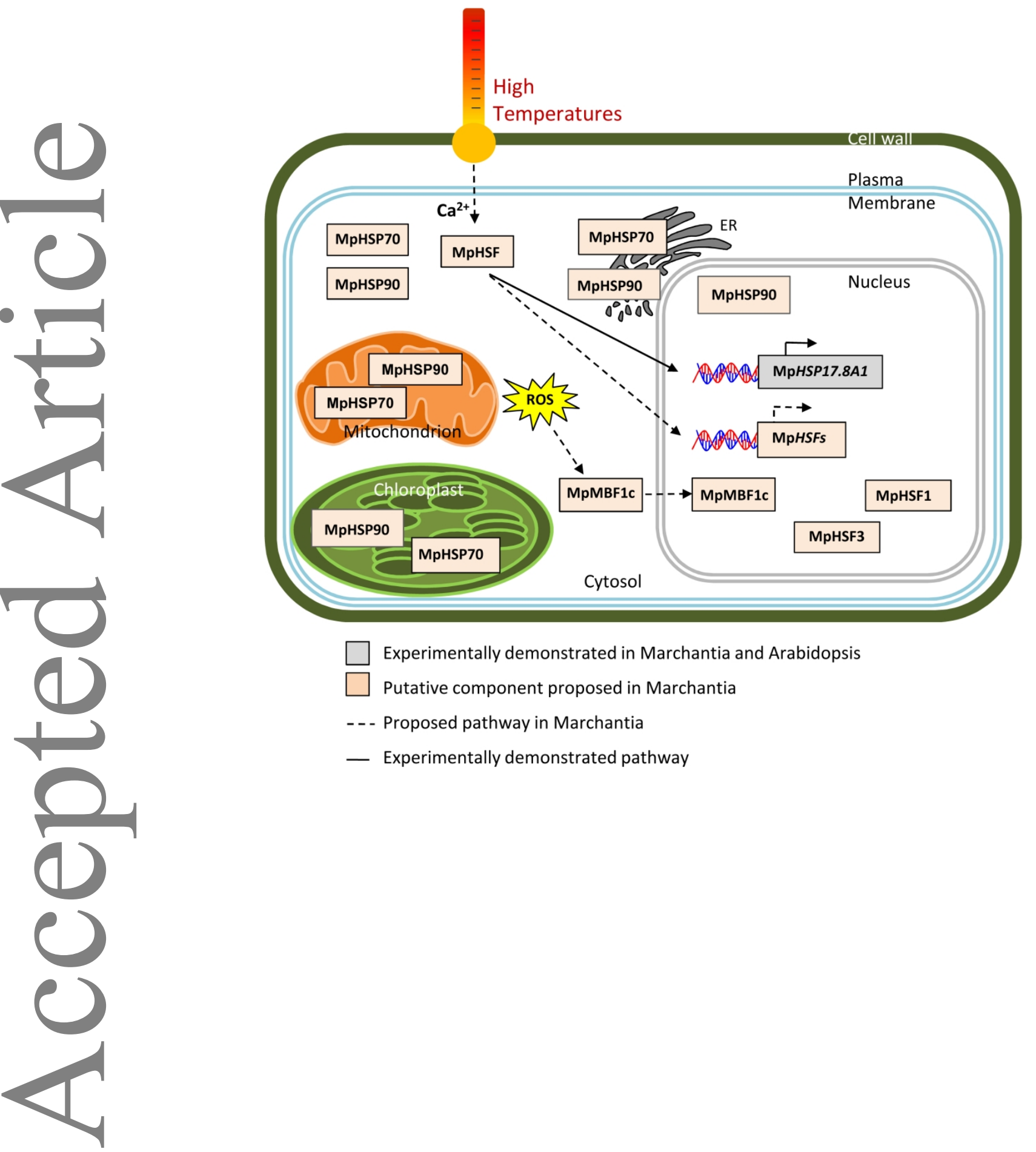

This article is protected by copyright. All rights reserved. 


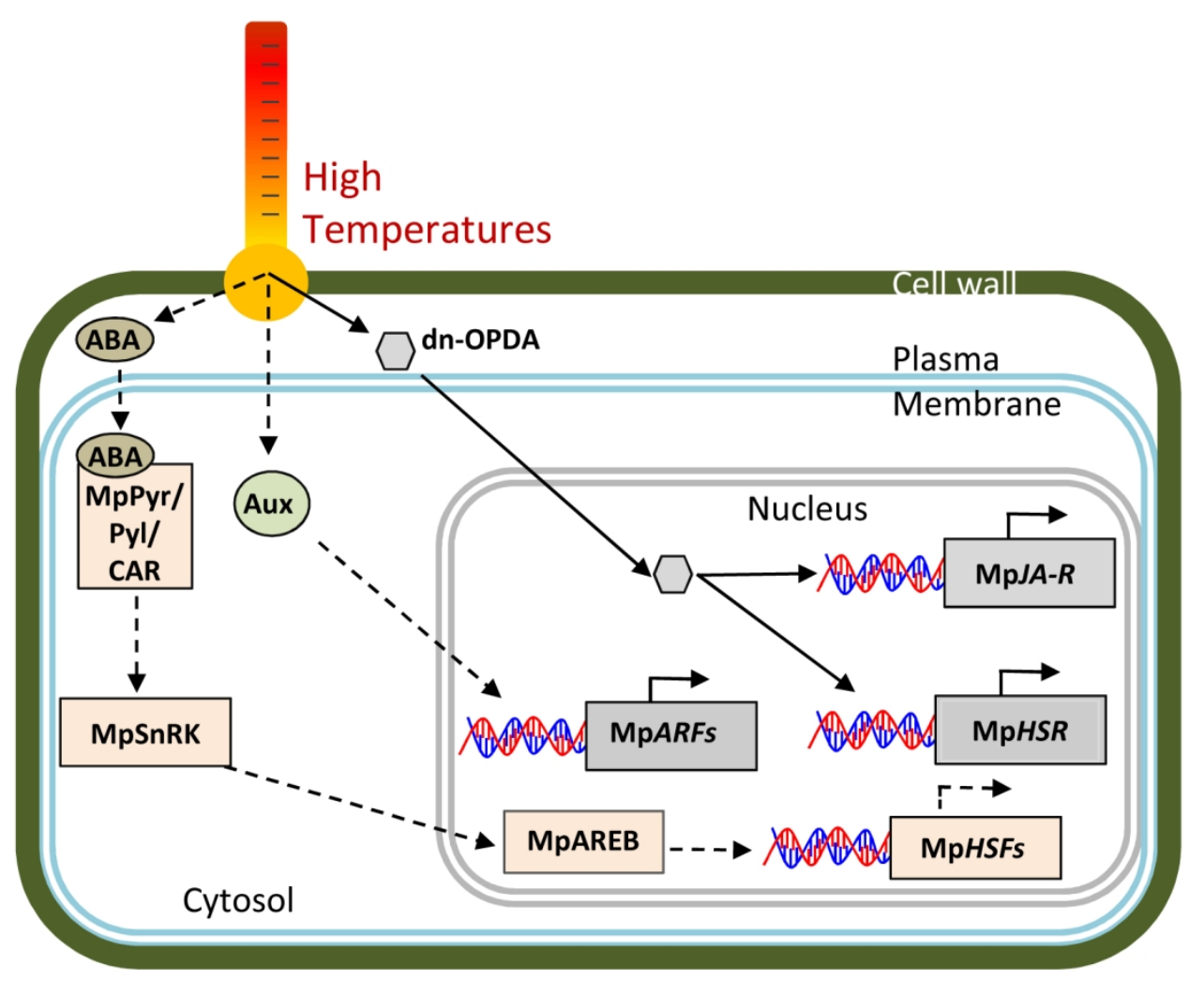

Experimentally demonstrated in Marchantia and Arabidopsis

Putative component proposed in Marchantia

Proposed pathway in Marchantia

- Experimentally demonstrated pathway 


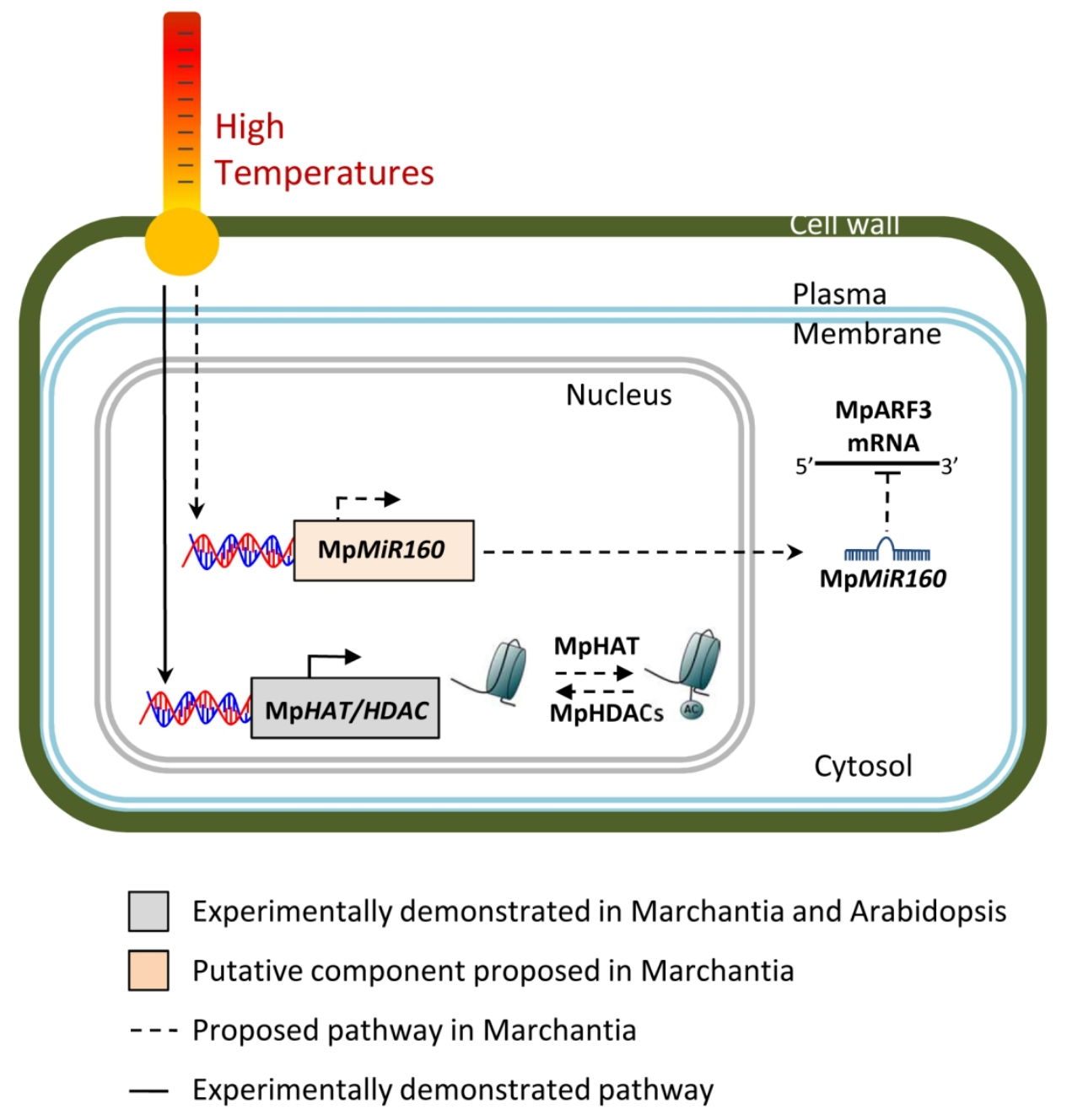

This article is protected by copyright. All rights reserved. 
High

Temperatures
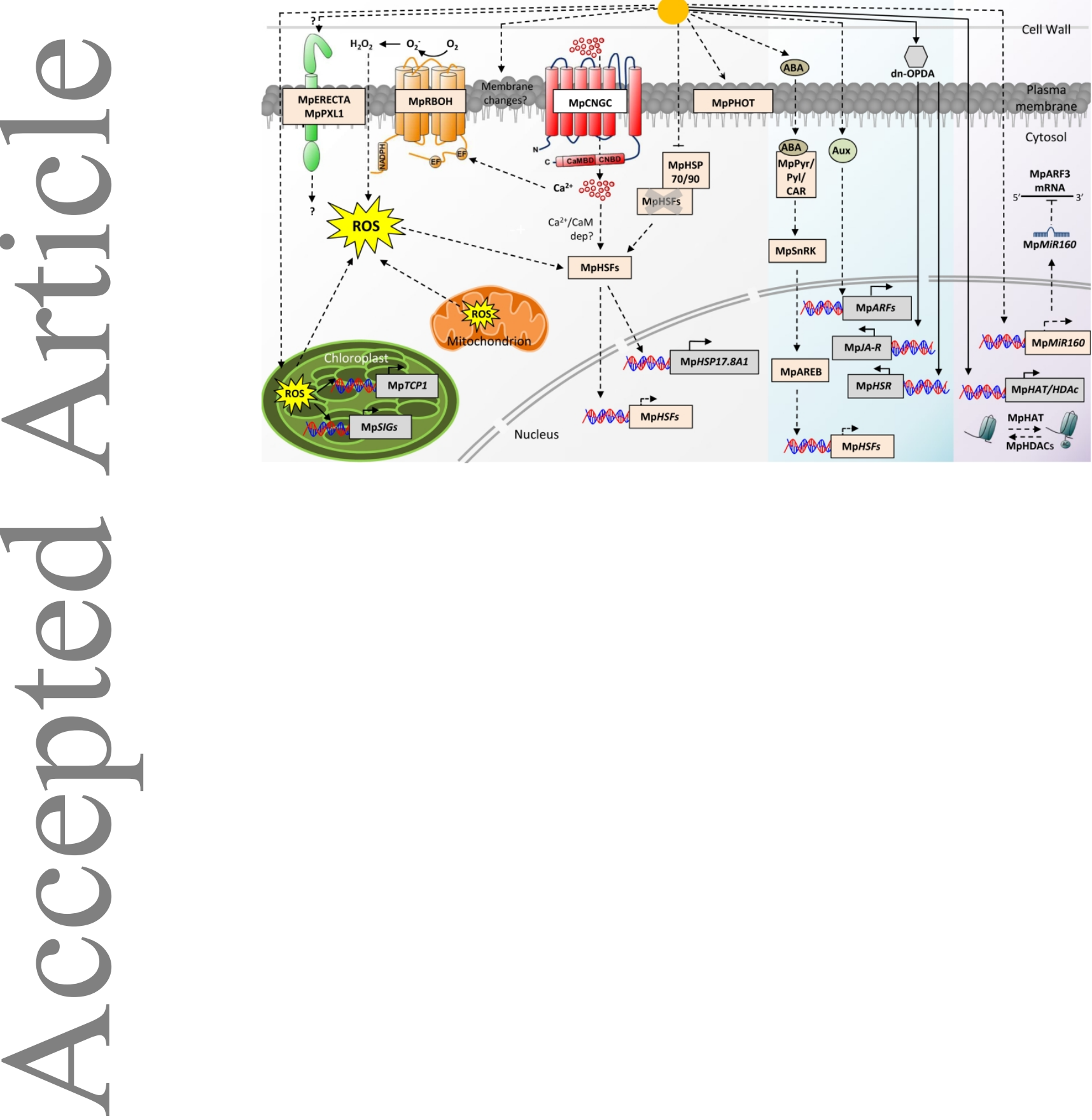

This article is protected by copyright. All rights reserved. 